\title{
Protozoa in respiratory pathology: a review
}

\author{
R. Martínez-Girón*, J.G. Esteban\#, A. Ribas ${ }^{\Uparrow}$ and L. Doganci ${ }^{+}$
}

\begin{abstract}
Among the micro-organisms that may affect the respiratory apparatus are the protozoa. The diseases they may give rise to constitute a relatively uncommon group of respiratory ailments with, in the majority of cases, an underlying clinical situation corresponding to states of suppressed immunity (AIDS, transplants, malign haemopathies, corticotherapy, etc.). Other factors, such as visits to endemic areas and immigration, also have to be taken into account.

In view of the probable increase in the number of cases and the appearance of new emerging diseases, it is the intention of the present work to review the publications available, in different fields of medicine, that refer to the principal kinds of protozoa (Entamoeba, Acanthamoeba, Balamuthia, Leishmania, Trypanosoma, Trichomonas, Lophomonas, Cryptosporidium, Cyclospora, Toxoplasma, Plasmodium, Babesia, Encephalitozoon, Enterocytozoon and Balantidium) and, at the same time, detail and comment on the latest findings on this subject.
\end{abstract}

KEYWORDS: Parasitic pulmonary diseases, protozoa, protozoal respiratory pathology

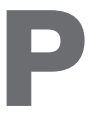

rotozoa are unicellular eukaryotic microorganisms. Their morphology is varied, and their physiology and metabolism are adapted to their needs; nutrition is heterotrophic in the parasitic forms and autotrophic in the freeliving ones, they have more or less complex life cycles, both free-living and parasitic, and in many cases, a vegetative form (trophozoite) and another resistant form (cyst).

Although at present there exists a tendency towards systematic unification on the basis of molecular phylogens of the ribosomic fraction of $18 S$ [1], the established classification of the protozoa of greatest interest [2] consists of five phyla: Sarcomastigophora, Apicomplexa, Microspora, Mixozoa and Ciliophora.

The effects of protozoa on the respiratory apparatus, as opposed to other localisations (intestine, liver, vagina, urethra, etc.), constitute a group of rare diseases [3], with the existence, in most cases, of an underlying clinical situation corresponding to certain states of suppressed immunity (AIDS, transplants, malign haemopathies, corticotherapy etc.), although other factors, such as visits to endemic areas and immigration, also have to be taken into account [4]

The mechanisms by means of which the protozoa affect the respiratory apparatus may be: direct damage to the parenchyma (e.g. toxoplasmosis); through a systemic inflammatory response by haematogenous dissemination (e.g. malaria); and contiguity with an adjacent lesion (e.g. amoebiasis)

Although many of the protozoa that are of medical interest may be cultivated, this technique is little used for diagnostic purposes, enhancing the importance of microscopic visualisation. This may be achieved either by fresh examination or by the employment of specific stains (Wheatley's trichromic, Giemsa, Heidenhain, Lugol, etc.). Furthermore, together with the electron microscope, there exist more specific diagnostic methods based on immunological analysis or molecular biology tests.

It is the intention of the present work to review the publications available, in different fields of medicine, that refer to the principal kinds of protozoa that may affect the respiratory apparatus, presenting them in a single monographic paper, and at the same time detail and comment on the latest findings on this subject, one which may well, in the relatively near future, open up new fields of research in this area of respiratory pathology.

The literature review was identified through electronic databases, such as MEDLINE, EMBASE and the Cochrane Database of Systematic Reviews. The search was performed using the keywords "protozoa", "lung" and "pulmonary infection", and the names of each kind of protozoon implicated in the study.
AFFILIATIONS

*Protozoal Respiratory Pathology Research Unit, and

- Protozoal Respiratory Pathology Research Unit, Fundación INCLÍNICA, Anatomical Pathology Service, Hospital Universitario Central de Asturias, Oviedo,

\#Dept of Parasitology, Faculty of Pharmacy, Universidad de Valencia, Valencia, Spain, and

+Infectious Diseases, Ondokuz Mayis University Medical Faculty, Samsun, Turkey.

CORRESPONDENCE

R. Martínez-Girón

Marqués de San Esteban

$22-2^{\circ} \mathrm{B}$

33206-Gijón

Spain

Fax: 34985507192

E-mail: rmartinezgiron@hotmail.com

Received:

February 122008

Accepted after revision:

May 232008

STATEMENT OF INTEREST

None declared. 
Peer-reviewed publications in English, French and Spanish languages, along with English-language abstracts of nonEnglish papers identified in the present research, were included. Inclusion or exclusion of each paper was decided mainly by considering the relevance of the article, journal impact factor, number of patients included in the work and pathological findings.

\section{PATHOGENIC AGENTS AND CLINICAL SITUATIONS}

Table 1 shows the different types of protozoa that may cause pathology in the respiratory apparatus. Preferred route and duration of therapy for each organism are summarised in table 2 .

\section{Phylum Sarcomastigophora}

This phylum includes the subphylum Sarcodina (amoebae) and Mastigophora (flagellates).

The general characteristic of the Sarcodina subphylum is that it presents mobile trophozoites, inconstant in shape, in the form of pseudopods, although some may present temporary flagellae. However, in the Mastigophora subphylum, the trophozoites are constant in shape and have one or two flagellae, occasionally associated with other organelles, both at the base and as undulating membranes.

\section{Genus Entamoeba}

Within this genus, the only species traditionally recognised as a pathogen for humans, who are its principal host and reservoir, is Entamoeba histolytica. This protozoon is distributed worldwide, although it is more frequent in countries where health conditions are deficient. Malnutrition, advanced age, pregnancy, immune suppression states, alcoholism and certain sexual practices are risk factors favouring its development. In the present context, visits to endemic areas (Africa, Asia and Central America) and immigration are two additional factors to be taken into account.

This is the agent responsible for clinical situations such as traveller's diarrhoea, amoebic diarrhoea and amoebic dysentery, all of which are consequences of infection of the large intestine, as well as for extraintestinal amoebiases due to trophozoites (fig. 1) acceding to the blood vessels and then being carried in the bloodstream to various organs, such as the liver, lung, brain, heart, skin, etc.

Pleuropulmonary infection by E. histolytica is, after that of the liver, the most frequent form of extraintestinal amoebiasis and occurs, in most cases, as a complication of a hepatic abscess (fig. 2a and b) due to fistulisation [6-8], with the lower lobule of the right lung being the area most frequently affected. However, the haematogenous path has also been described as a cause of pulmonary lesions due to E. histolytica $[9,10]$.

The clinical situation largely depends on the associated pulmonary pathology, frequent symptoms being fever, cough, haemoptysis and pleuritic pain $[11,12]$. On occasion, a hepatic abscess may provoke venous compression and be the cause of respiratory distress and alterations in arterial gasometry [13]. The appearance of a purulent fluid of a chocolate-like appearance (often described as anchovy paste) following the puncture of an abscess, discharge, or through vomiting, are highly suggestive signs [14].
Radiographic findings are variable, ranging from fine basal reticular patterns, with focal areas of atelectasis, to extensive infiltrates. Elevation of the right diaphragm (fig. 3), hepatobronchial fistula, lung abscess, pleural effusion or discharge and bronchopleural fistula with pyopneumothorax are other lesions described [15-17].

Procedures such as sputum cytology or fine-needle puncture aspiration have proved their usefulness in the diagnosis of pulmonary lesions in which the diagnosis of pulmonary amoebiasis was not initially suspected $[18,19]$. Moreover, in cases of pulmonary amoebiasis without data indicating intestinal and/or hepatic repercussions, which have to be distinguished from other processes, such as bacterial abscesses, neoplasias, empyema and tuberculosis [20], the combination of trophozoite visualisation through cytological sputum examination with DNA extraction techniques has proved to be of

\section{TABLE 1 Protozoa involved in pathology of respiratory} apparatus

\section{Kingdom: Protista}

Subkingdom: Protozoa

Phylum: Sarcomastigophora

Subphylum: Sarcodina

Superclass: Rhizopoda

Order: Amoebida

Family: Endamoebidae (Genus: Entamoeba)

Order: Schyzopyrenida

Family: Leptomyxidae (Genera: Acanthamoeba and Balamuthia)

Subphylum: Mastigophora

Order: Trichomonadida

Family: Trichomonadidae (Genera: Trichomonas, Tritrichomonas and Tetratrichomonas)

Order: Hypermastigida

Family: Hypermastigidae (Genus: Lophomonas)

Order: Kinetoplastida

Family: Trypanosomatidae (Genera: Leishmania and Trypanosoma)

Phylum: Apicomplexa

Class: Sporozoea

Subclass: Coccidia

Order: Eucoccidiida

Family: Cryptosporidiidae (Genus: Cryptosporidium)

Family: Eimeriidae (Genus: Cyclospora)

Family: Sarcocystidae

Subfamily: Toxoplasmatinae (Genus: Toxoplasma)

Family: Plasmodiidae (Genus: Plasmodium)

Subclass: Piroplasmia

Order: Piroplasmida

Family: Babesiidae (Genus: Babesia)

Phylum: Microspora

Class: Microsporea

Order: Microsporidia

Family: Glugeidae (Genus: Encephalitozoon)

Family: Pereziidae (Genus: Enterocytozoon)

Phylum: Ciliophora

Class: Kinetofragminophorea

Order: Trichostomatida

Family: Balantidiidae (Genus: Balantidium) 
TABLE 2 The most relevant first-choice drug for protozoa in respiratory pathology

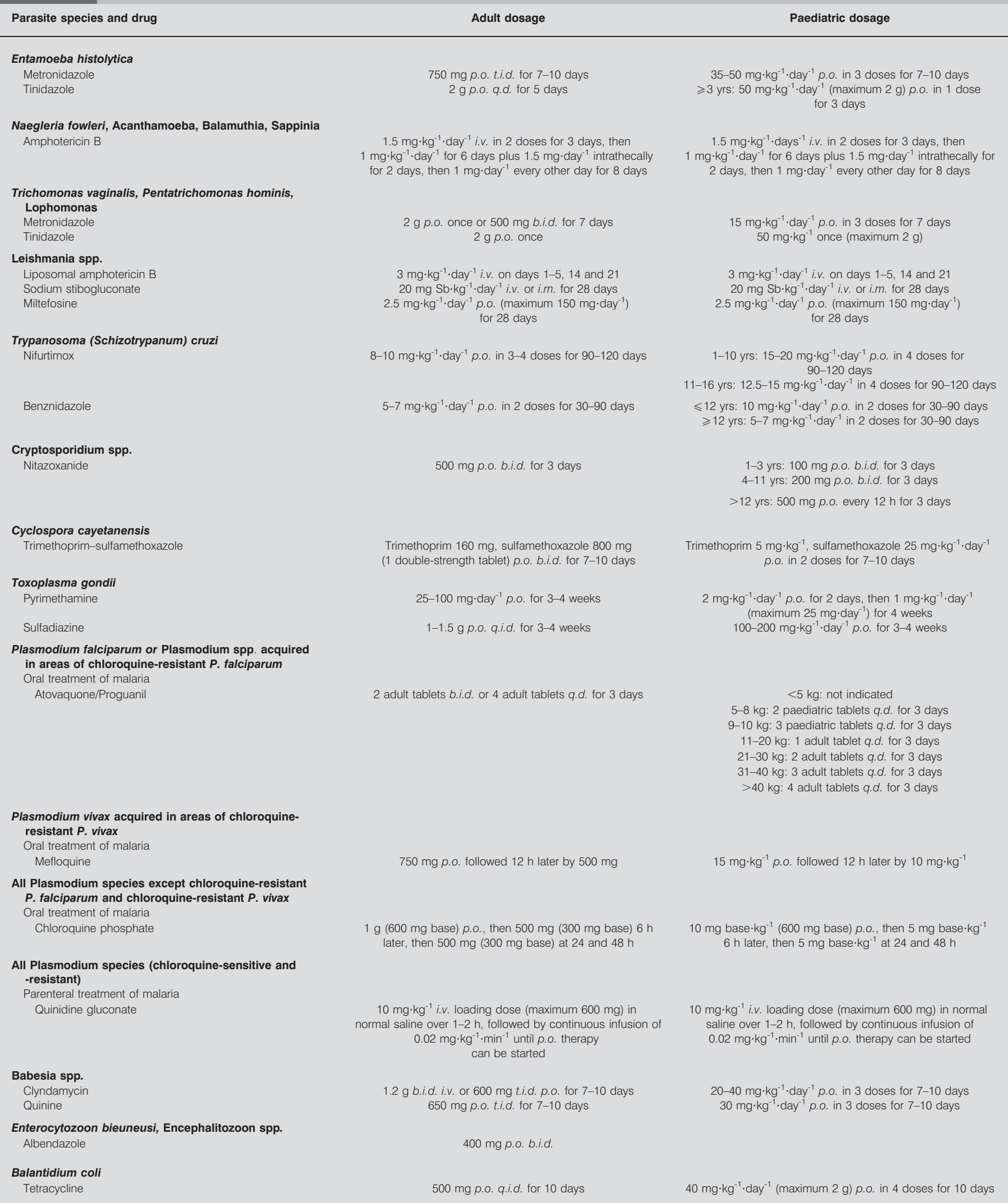

Data are taken from [5]. 


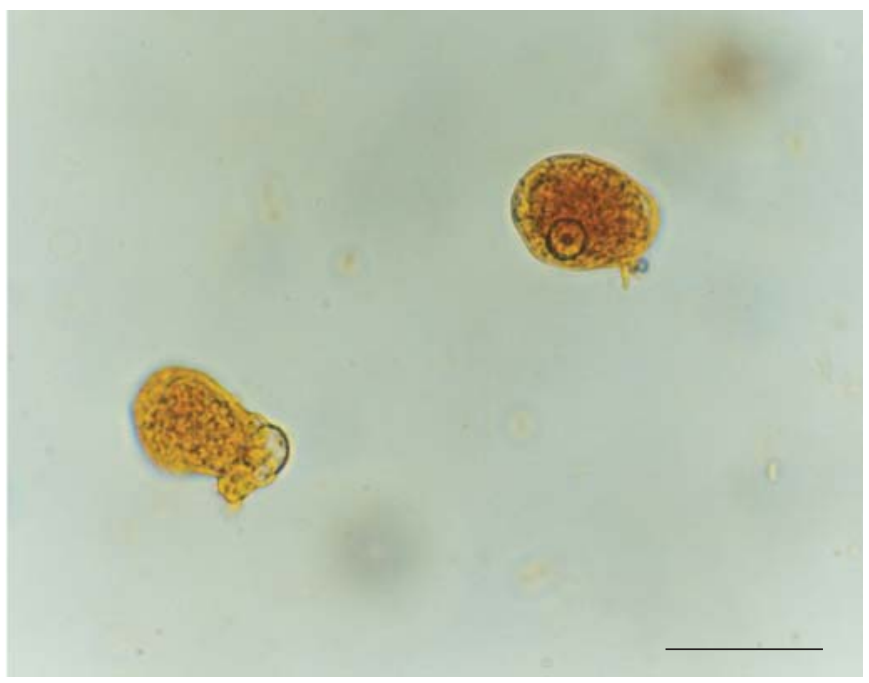

FIGURE 1. Entamoeba histolytica: two trophozoites in faecal iodine-stained wet mount. Scale bar $=15 \mu \mathrm{m}$.

great utility [21]. It is important to note that, in sputum samples, a nonpathogenic species, Entamoeba gingivalis, may appear, which is present in the oral cavity [22] and may be confused with E. histolytica [23, 24]. Complementary laboratory tests, such as serological detection of antibodies, also help establish a definitive diagnosis.

\section{Genera Acanthamoeba and Balamuthia}

A series of protozoa ubiquitously present in nature (they may be isolated from earth, air and water) and which may be pathogenic for humans, whether their condition is normal or immunosuppressed, have been grouped under the denomination "free-living amoebae" [25]. Knowledge of these protozoa is important for two reasons: on the one hand, they cause pathologies in various organs (brain, cornea, skin, lung, etc.), while on the other, they may harbour and transmit pathogenic bacteria [26-29], some of which, such as Legionella pneumophilia
$[30,31]$, mycobacterias [32, 33], Chlamydia pneumoniae [34] and Francisella tularensis [35], have important repercussions on the respiratory system. This last factor may have clinical relevance, as a series of micro-organisms associated with amoebae are mentioned as agents causing nosocomial pneumonia [36].

Of the genera known at present, only four are associated with human pathology: Acanthamoeba, Balamuthia, Naegleria and Sappinia. Studies carried out on experimental animals have shown that certain species, such as Naegleria fowleri, Acanthamoeba castellanii and Acanthamoeba polyphaga may cause direct damage to the pulmonary parenchyma in the form of pneumonitis, with thickening of the alveolar walls, mononuclear inflammatory infiltrate and development of hyaline membranes in the alveolar spaces [37-40]. In the case of humans, only Acanthamoeba spp. and Balamuthia mandrillaris have been related with pulmonary pathology [41-43].

Pneumonitis is the most frequent lesion, with the presence of cystic forms and trophozoites in the alveolar spaces. Radiological examination reveals diffuse areas of alveolar consolidation. The identification of trophozoites in bronchoalveolar lavage samples and their subsequent cultivation help establish a diagnosis [44, 45]. In other types of samples, such as nasal exudates, the presence of amoebae (Naegleria spp. and Acanthamoeba spp.) has been described [46].

\section{Genera Trichomonas, Tritrichomonas and Tetratrichomonas}

The literature reviewed shows that the three species of Trichomonas that are pathogenic in humans (Trichomonas vaginalis, T. tenax and T. hominis) are implicated in infectious processes that affect the respiratory apparatus.

Pulmonary infection by $T$. vaginalis (fig. 4) may appear in newborn babies $[47,48]$, adults presenting suppressed immunity $[49,50]$ and in patients with acute respiratory distress syndrome [51, 52]. In the case of newborn babies there exists the antecedent of vaginal birth by mothers infected with the protozoon $[53,54]$. Complications may be immediate, in the form of respiratory difficulty [55], or long term [56]. Detection
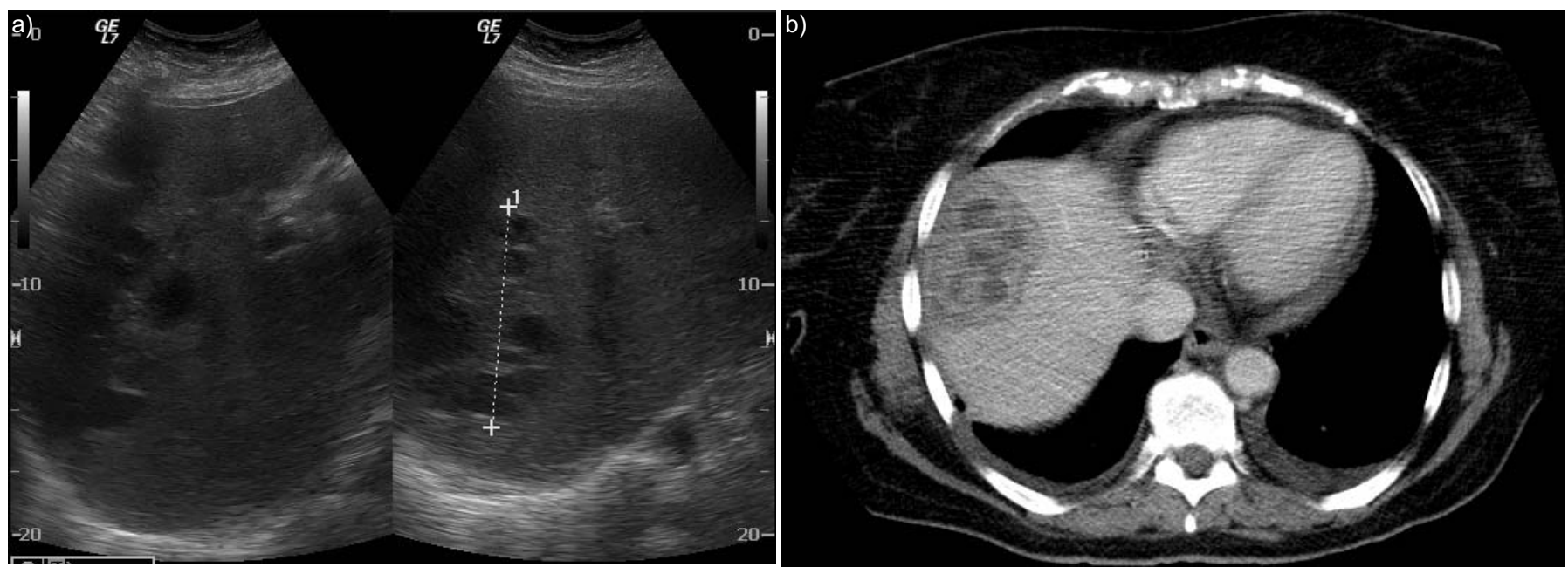

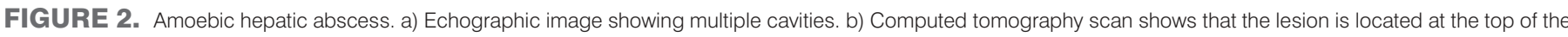
right hepatic lobule, very near to the diaphragmatic cupola. 


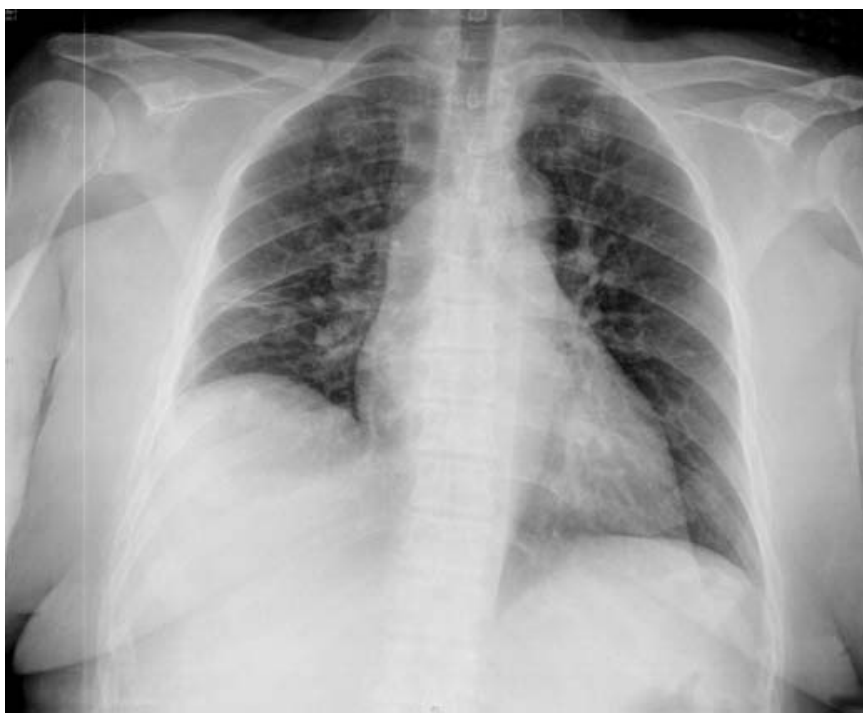

FIGURE 3. Thoracic amoebiasis. Thorax radiograph showing elevation of the right diaphragmatic cupola, and extensive infiltrates.

of the presence of mobile forms of the micro-organism in secretions of the respiratory tract, and their subsequent cultivation in an appropriate medium, are procedures used in the diagnosis.

With regard to $T$. tenax, present in the oral cavity and frequently found in dental plaque, this is the species most frequently described in the literature reviewed. The appearance of this micro-organism is the most frequent cause of the development of a pulmonary pathology [57]; factors that predispose towards its development are poor dental hygiene, malnutrition, alcoholism and prior debilitating or pulmonary diseases (carcinoma, abscess, bronchiectasis, etc.) [58, 59]. In these cases, pleural discharge is the most common complication [60-63], and the presence of mobile forms is observed in fresh preparations of the fluids obtained. Giemsa staining is also quite useful. In other kinds of samples, such as bronchoalveolar lavage, its presence has been described, together with numerous eosinophils, in a patient with a history of asthma [64]. Identification of the species is possible using molecular biology techniques $[65,66]$.

T. hominis, also known as Pentratrichomonas hominis, is the species that appears least often in the literature $[67,68]$. As it is a micro-organism located in the intestine, it is supposed that it may reach the respiratory apparatus by aspiration or through a bronchoenteral fistula. A necrotising pulmonary abscess and pleural effusions are the pathological situations described.

In the genera Tritrichomonas and Tetratrichomonas there are many species that may be pathogenic for various animals (sheep, pigs, cats, birds, etc.). Of these, Tritrichomonas foetus and Tetratrichomonas gallinarum are two of the most representative. It has recently been suggested that some of these species originating in animals may have become adapted to humans. Proof of this are two studies that, by means of biological tests, have demonstrated genetic sequences of these protozoa in samples from the human respiratory apparatus $[69,70]$. These findings have been recognised as opening up an important new field of research [3].

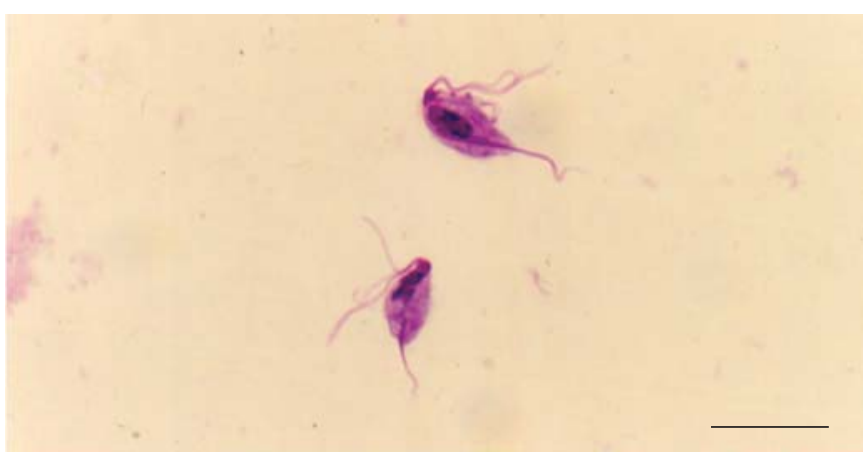

FIGURE 4. Trichomonas vaginalis: two Giemsa-stained trophozoites. Scale bar $=15 \mu \mathrm{m}$.

\section{Genus Lophomonas}

Protozoa belonging to this genus are found as symbionts in the intestine of certain arthropods, such as termites and cockroaches, contributing to the process of digestion of some materials, such as cellulose.

In the published literature, two studies from China are mentioned in which protozoa of the Hypermastigida order are related to pulmonary pathology, responding to metronidazole therapy [71, 72]. Furthermore, the species Lophomonas blattarum is implicated in four cases of patients undergoing renal transplant who developed pulmonary pathology; in all these cases, therapeutic response with metronidazole was also demonstrated [73].

Protozoa forms not so far catalogued but which, from their morphological and staining characteristics, are presumed to be flagellated protozoa (fig. 5a and b), have been described in the sputum of asthmatic patients [74], nasal secretions of patients with allergic rhinitis [75] and sputa of immunodepressed patients, especially those with AIDS [76, 77].

A striking fact is the finding of similar flagellated protozoa in intestinal extracts of dust mites and cockroaches, establishing a possible nexus between these micro-organisms and respiratory allergy [78-80].

\section{Genus Leishmania}

This genus includes a great number of species, noteworthy among which are L. donovani, L. tropica, L. major and L. infantum (present in the Mediterranean basin), with a biological cycle integrated by an extracellular form or promastigote in the intestinal tract of phlebotomes (small insects similar to mosquitoes), and an intracellular form or amastigote that mainly attacks the cells of the reticuloendothelial system. Leishmaniasis is endemic in regions of Asia, Africa, Central and South America and the Mediterranean area of Europe [81].

There are three forms of leishmaniasis: cutaneous, mucocutaneous and visceral (kala-azar). Many of the forms that affect the viscera (lungs, larynx, gastrointestinal tract, etc.) are considered opportunistic infections in cases of AIDS [82, 83].

In animal experimentation models, the pulmonary lesion caused by Leishmania spp. is characterised by chronic diffuse interstitial pneumonitis with thickening of the alveolar septa due to the depositing of collagen and a cellular exudates 


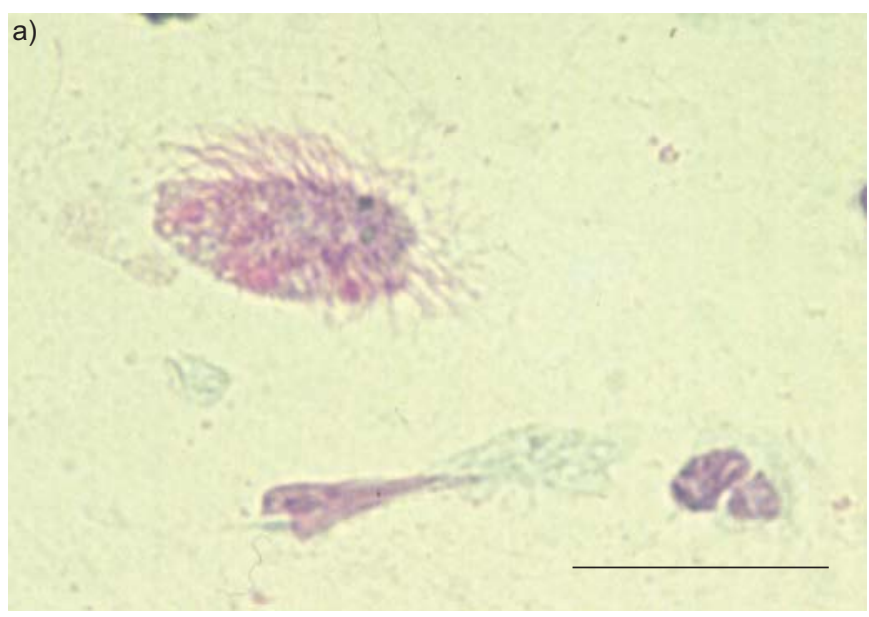

b)

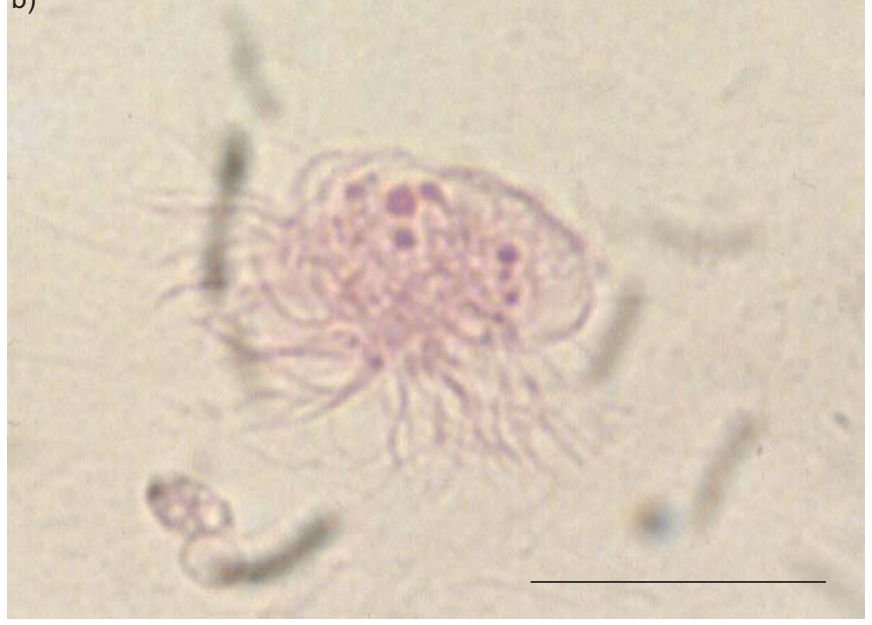

FIGURE 5. Multiflagellated protozoa on sputum smears from AIDS patients (Papanicolaou stain). Scale bars $=20 \mu \mathrm{m}$.

formed principally by macrophages, lymphocytes and plasmatic cells [84]. A similar pulmonary pathology involving foci of septal fibrosis and interstitial pneumonitis with a predominance of mononuclear cells has also been described in humans [85]. Other forms in which the disease presents itself are granulomatous inflammation of the bronchial mucosa and mediastinal lymph nodes [86], and the development of pleural effusions with the presence of the intracellular protozoon in macrophages [87, 88]. In other types of samples of the respiratory apparatus, such as transbronchial biopsy [89] and bronchoalveolar lavage [90, 91], the presence of Leishmania amastigotes has also been detected.

Infection of the mucosa of the larynx is another complication of leishmaniasis. This infection is frequently encountered in AIDS patients [92, 93], although cases have also been described in immunocompetent patients [94]. In these latter cases, differential diagnosis with respect to neoplasic processes has been proposed [95]; apart from the histological findings, the demonstration of specific DNA sequences in the tissues affected by means of molecular biology techniques is also very useful [96].

Direct observation of the parasite (fig. 6) is one of the best methods of diagnosis and, in the case of visceral leishmaniasis, is usually carried out in bone marrow aspirates by means of haematological stains. Nowadays, molecular biology techniques are an alternative that should also be considered.

The use of medicines such as pentavalent antimonial derivatives is one of the treatments of choice in leishmaniasis, although other substances such as paromomycine and liposomal amphoterycine B are effective alternatives [97].

\section{Genus Trypanosoma}

The Trypanosoma genus comprises various species of haemoflagellated protozoa transmitted to man by the bite of flies and bedbugs. Their names reflect the region of the planet they inhabit: T. brucei rhodesiense and T. brucei gambiense (Africa), responsible for sleeping sickness or African trypanosomiasis; and T. (Schizotrypanum) cruzi (South America), responsible for Chagas' disease or trypanosomiasis Americana. It is the latter that may affect the respiratory apparatus, either in organs such as the heart and oesophagus [98], or during pregnancy through the placenta (the congenital form of the disease).

In a wide study of post mortem cases both myocarditis and megaoesophagus were the cause of a series of pulmonary complications, such as pleural effusion, thromboembolism, aspiration pneumonia, pulmonary abscess, bronchiectasis and tuberculosis [99].

In experimental animals it has been demonstrated that parasitaemia due to $T$. cruzi is the cause of pneumonitis [100], with changes in the pulmonary parenchyma, such as thickening of the alveolar walls due to proliferation of type II pneumocytes, macrophages and mononuclear inflammatory infiltration with oedema. The alveolar spaces contain liquid, fibrin, hyaline membranes and erythrocytes. The presence of micro-organisms was observed in the walls of the bronchia accompanied by an inflammatory reaction. Micro-organisms also appeared in the walls of the large vessels.

In cases of the congenital form of the disease, pneumonitis is the most frequent lesion, with the presence of amastigotes in lungs, placenta membranes and the umbilical cord [101].

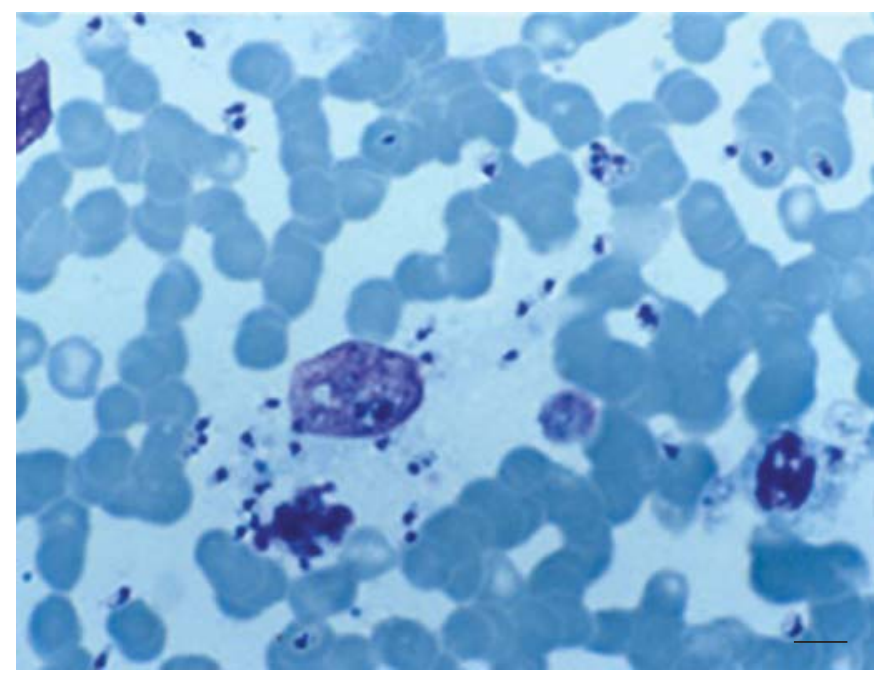

FIGURE 6. Leishmania infantum: Giemsa-stained amastigotes in a smear from the bone marrow. Scale bar $=7 \mu \mathrm{m}$. 
During the acute phase of Chagas' disease, numerous parasites that can be detected by direct parasitological tests appear in peripheral blood. Microscopic observation of fresh blood can easily reveal the presence of the parasite, thanks to its motility.

Blood smears in fine thin film and thick drop, appropriately stained, allow the typical morphological characteristics of the parasite to be observed (fig. 7). If the degree of parasitaemia is low, it is vital to use concentration methods such as the microhaematocritic. Xenodiagnosis (visualisation of the parasite in the faeces of the vector) and haemocultivation are the established indirect methods, the sensitivity of which depends on the degree of patient parasitaemia. Moreover, there is widespread use of serological and molecular methods.

Nifurtimox, a derived from nitrofurane, and benznidazole (a nitroimidazole) are practically the only medicines used to treat Chagas' disease.

\section{Phylum Apicomplexa (Sporozoa)}

These protozoa are intracellular parasites with one exclusive characteristic, the presence of what is known as the "apical complex", an intracytoplasmic structure related with the adhesion to and invasion of the host cells. Various genera of this phylum may act on the respiratory apparatus.

\section{Genus Cyclospora}

Of the various species belonging to this genus, only Cyclospora cayetanensis is pathogenic for man; the micro-organism is acquired following the ingestion of sporulated oocysts through contaminated food and water [102]. In immunocompetent individuals, depending on their immune state, infection may be asymptomatic or provoke a self-limited diarrhoea episode (cases frequently occur following visits to tropical countries). In immunodepressed patients, especially in AIDS cases, the intestinal episode is more serious and tends to become chronic.

Although effects of Cyclospora on the respiratory apparatus have not so far been identified, two cases have been documented of the presence in sputum of oocysts, corresponding to the

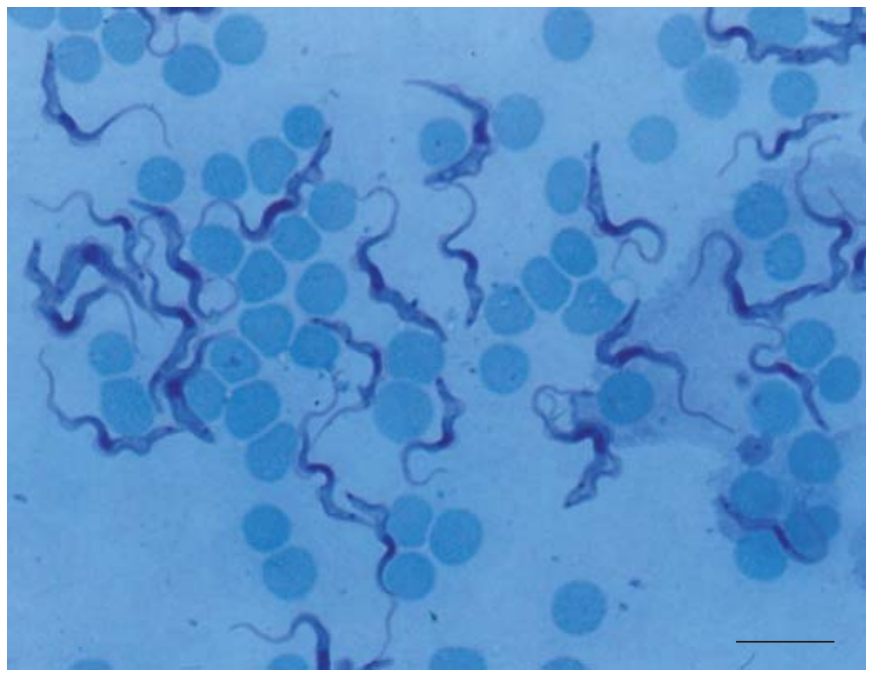

FIGURE 7. Trypanosoma brucei gambiense: Giemsa-stained trypomatigotes in a thin blood film. Scale bar $=14 \mu \mathrm{m}$. species C. cayetanensis, with concomitant infection by tuberculosis in both cases [103, 104].

Microscopic identification of Cyclospora oocysts (round structures $7-10 \mu \mathrm{m}$ in diameter and with a visible wall) can be carried out either in fresh samples or using special staining techniques (trichromic, modified Ziehl-Neelsen, safranine, calcofluor white, etc.). Detection methods based on the PCR technique also exist. The treatment of choice is the combination of trimethoprim plus sulfamethoxazole.

\section{Genus Cryptosporidium}

The genus Cryptosporidium comprises 13 species of intracellular enteric protozoa widely distributed in animals, especially birds, cattle and sheep. In humans, the species most often detected are C. paroum, C. hominis and C. meleagridis [105]. The infection is acquired by the ingestion of oocysts (fig. 8) through water and food contaminated with faecal matter, contact with animals, or from person to person.

The principal clinical expression of cryptosporidiosis is watery diarrhoea of variable duration, the process being self-limiting in immunocompetent persons, and tending to become chronic in immunodepressed patients, among whom it may prove fatal. It is among this latter group that clinical forms of extraintestinal repercussions may be observed [106].

All the documented cases of invasion of the respiratory apparatus by Cryptosporidium correspond to immunodepressed patients, the principal cause being the appearance of AIDS [107-116]. Other processes also exist, such as those corresponding to malign haematological pathologies [117] and bone marrow transplant recipients [118, 119]. Although the mechanism by which Cryptosporidium colonises the respiratory apparatus is not clear, aspiration of gastric content and haematogenous dissemination facilitated by macrophages originating in an intestinal focal point have been proposed as possible routes [120].

Both clinical observation and radiography tend to be imprecise, the symptoms most often referred being persistent

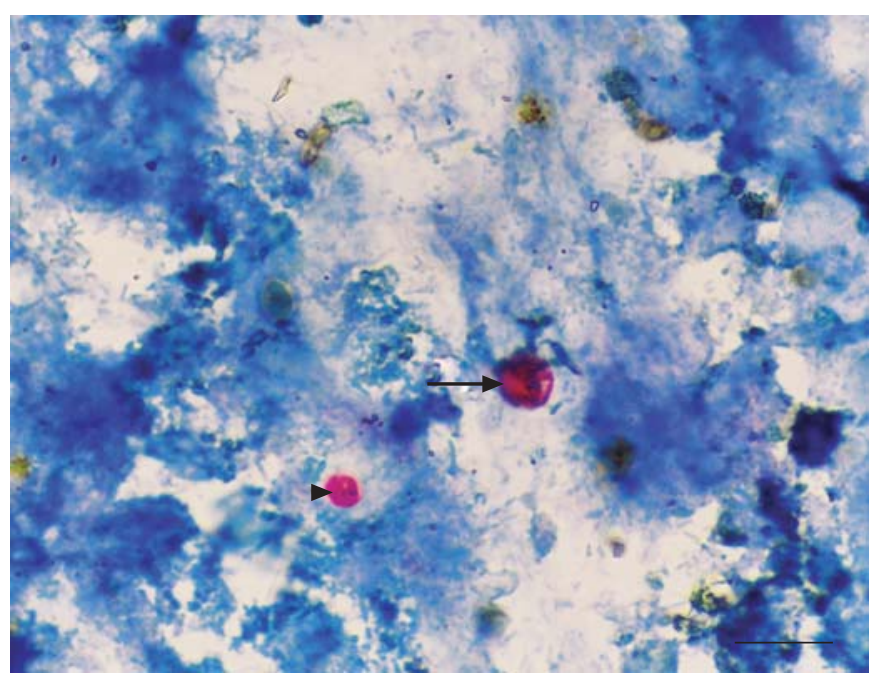

FIGURE 8. Cryptosporidium sp. oocysts (arrowhead) and Cyclospora cayetanensis oocysts (arrow) in red in a modified acid-fast stained faecal smear. Scale bar $=10 \mu \mathrm{m}$. 
productive cough, fever, dyspnoea and tachypnoea, in some cases requiring mechanical ventilation due to respiratory failure and hypoxaemia. On chest radiographs, the most commonly observed pattern is that of interstitial pneumonia.

Studies in experimental animals subjected to immunosuppression have demonstrated that Cryptosporidium may directly damage the respiratory epithelium [121-123], especially noteworthy being the presence of tracheitis with scaly metaplasia and submucous lymphocyte infiltration, peribronchial glandular hyperplasia, loss of cilia and both nuclear and cytoplasmatic changes. The occupation by a purulent exudate in the bronchial cavities, with numerous micro-organisms adhering to the epithelial surface, is also described. Thickening of the intra-alveolar walls with an inflammatory infiltrate based on macrophages and lymphocytes was observed and also, in the alveolar spaces and even in macrophages, free micro-organisms.

These same alterations have been described in post mortem findings from patients who died of respiratory failure; data also exist regarding diffuse alveolar damage, especially hyperplasia of type-II pneumocytes and interstitial fibrosis.

Despite this, even when the autopsy confirms the presence of Cryptosporidium in lung tissue, it is sometimes difficult to confirm its implication in death owing to the fact that other pathogens are also present in the bronchial tree [124].

The presence both of noncystic forms of the protozoon (sporozoites and merozoites), free or in macrophages, and of oocysts (with a wall, spherical in shape and having a diameter of $4-6 \mu \mathrm{m})$ can be demonstrated in samples such as sputum, tracheal aspirate and bronchoalveolar lavage [125]. Staining methods such as the modifications of Kinyoun and ZiehlNeelsen and staining with auramine fluorescence are useful here. Molecular biology techniques help in determining the species of the parasite [126].

Paromomycin and azithromycin are the drugs of choice for the treatment of this protozoosis [127], with inhalation a route to be borne in mind [128].

\section{Genus Toxoplasma}

Toxoplasma gondii, an obligate intracellular protozoon, is the agent causing toxoplasmosis, an infectious disease found worldwide that affects humans and many animal species alike, cats being the definitive host of the parasite. In its life cycle, T. gondii adopts three forms: oocyst, found in the intestine of the cat and excreted to the exterior in its faeces; tachyzoite, the mature form responsible for parasitaemia; and bradyzoite, which forms dormant intracellular cystic aggregates and is responsible for the immune state of the individual.

In healthy persons, toxoplasmosis causes asymptomatic infection or subclinical forms (fever and lymphadenopathies). The most serious form is congenital toxoplasmosis (contracted by the mother during pregnancy), which affects immunodepressed women and is responsible for systemic infections.

Although pulmonary toxoplasmosis may develop in immunocompetent humans [129], there is in most cases a severe deficiency in the immune system. It is the second or third most frequent systemic infection among immunodepressed persons after brain and cardiac locations [130, 131]. Apart from AIDS [132-136], other processes, such as malign haematological pathologies and organ transplants, are also important causes of pulmonary toxoplasmosis [137-143]. In the majority of these cases, the most widely accepted hypothesis regarding the development of pulmonary toxoplasmosis is the reactivation of a previously latent infection [144, 145], the levels of interferon-$\gamma$ and the activity of alveolar macrophages being important causative factors. Furthermore, experimental studies on animals have revealed changes in the levels of interleukins segregated by T-helper type-1 lymphocytes in the lung in cases of reactivation of the infection by T. gondii [146].

The most frequent clinical symptoms are fever, cough, laboured breathing, tachypnoea and dyspnoea, with this latter, in some cases, leading to hypoxaemia with acute respiratory distress syndrome, which is one of the main causes of death among the patients [147-149].

Radiological examination usually reveals two patterns: the typical bilateral diffuse infiltrate (fig. 9), indistinguishable from other processes such as pneumonia caused by Pneumocystisis jiroveci; and a thick nodular bilateral infiltrate, which may be of use in differential diagnosis [150]. In general, these effects reveal interstitial pnemonitis and alveolar condensation. The existence of concomitant pleural effusions is another of the effects described. The anatomopathological examinations carried out, either in pulmonary biopsies or during necropsies, show lesions relating to the state and intensity of the infection [135]. Macroscopically, the lungs appear congested, with petechial haemorrhages and areas of consolidation. Histopathology shows interstitial pneumonitis with inflammatory lymphocyte infiltrate, diffuse alveolar

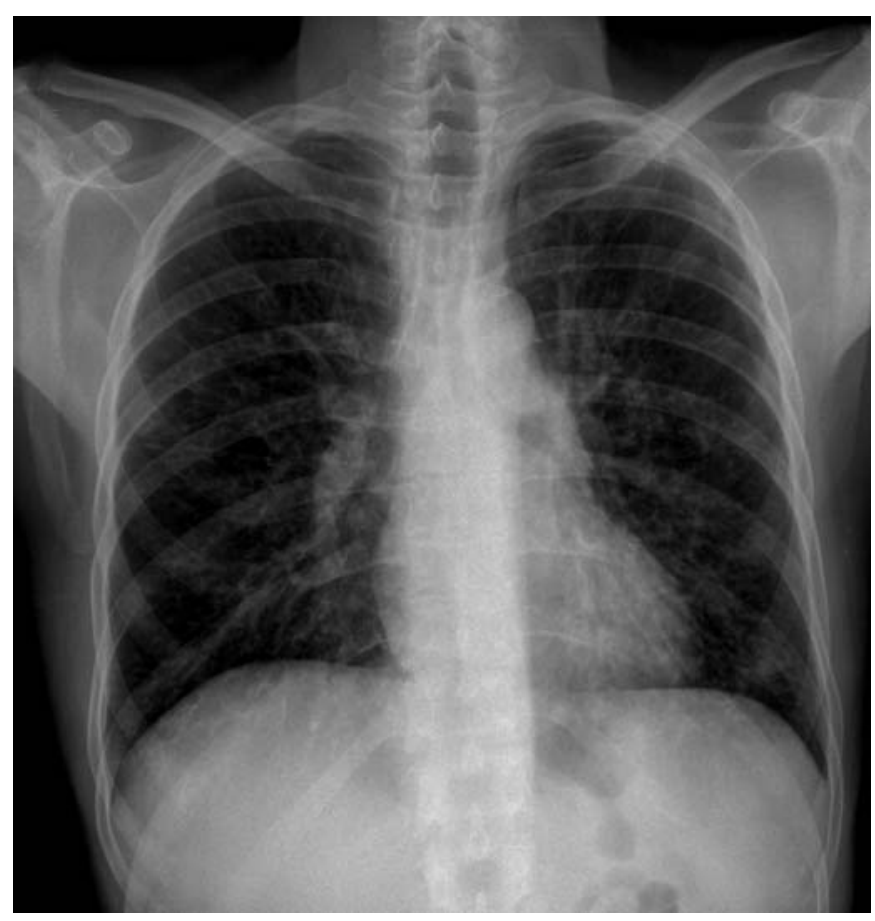

FIGURE 9. Pulmonary toxoplasmosis in a bone marrow transplanted patient showing bilateral diffuse infiltrates. 
damage with fibrinous alveolar exudates and the formation of alveolar hyaline membranes. There are usually numerous alveolar macrophages, which contain cysts of the parasite. Necrotising pneumonia appears as a more advanced lesion, characterised by extensive areas of parenchymatose necrosis and the presence of numerous tachyzoites, both extracellular and intracellular. In the cytological smears prepared from pleural effusions and stained with the May-Grünwald-Giemsa technique, the visualisation of many tachyzoites located extracellularly and intracellularly of polymorphonuclear leukocytes and macrophages is described [151, 152].

Various diagnostic procedures permit visualisation of the parasite in samples from the respiratory apparatus, one of the most significant being bronchoalveolar lavage [153-156] with Giemsa staining of the samples. In the sputum T. gondii also appears, this being an alternative diagnostic route if invasive techniques cannot be carried out [157]. In cases in which infection is suspected, or in which the micro-organisms are not observed, techniques such as PCR may be of great use [158, 159].

The most appropriate therapeutic measures are the combination of pyrimethamine and sulfadiazine administered to prevent haematological complications, or the substitution of sulfadiazine by clindamycin. Alternatives to these combinations are azithromycin and doxycycline. Apart from therapy, in immunodepressed patients primary prevention and appropriate prophylaxis against $T$. gondii may significantly mitigate pulmonary repercussions [160].

\section{Genus Plasmodium}

This genus comprises the intracellular protozoa that are responsible for malaria. The disease is endemic in $>90$ countries, affects 200-300 million people each year and, each year, is responsible for the death of $\sim 3$ million. It is, therefore, one of the diseases with highest morbidity and mortality. Four of the species belonging to this genus affect humans: $P$. falciparum, $P$. malariae, $P$. ovale and $P$. vivax. The disease is transmitted by the bite of the female Anopheles mosquito, and the Plasmodium has a life cycle consisting of an asexual stage in human hosts, with extraerythrocytic and intraerythrocytic phases, and a sexual stage that develops in the mosquito.

In the current authors' environment, malaria is one of the principal imported acute diseases with pulmonary manifestations [161, 162]. P. falciparum and P. vivax (fig. 10) are the species that most frequently affect the lungs, while $P$. ovale and $P$. malariae are the rarest [163]. The groups principally affected are children, pregnant women and travellers to countries where the disease is endemic [164].

Pulmonary oedema is the principal manifestation of the effects of malaria on the lung [165], especially in cases involving $P$. falciparum and, to a lesser extent, P. vivax [166]. The increased permeability of the alveolar capillaries appears to be the principal mechanism by which the plasmatic liquid fills the alveolar spaces [167]. In vitro experimental models have demonstrated that the adherence of the infected erythrocytes to the vascular epithelium, through various molecules (intercellular adhesion molecule-1, E-selectin, vascular cell adhesion molecule- 1 , etc.), is one of the main factors provoking capillary damage with subsequent increase in permeability [168, 169]. Another frequent pulmonary complication of malaria is acute

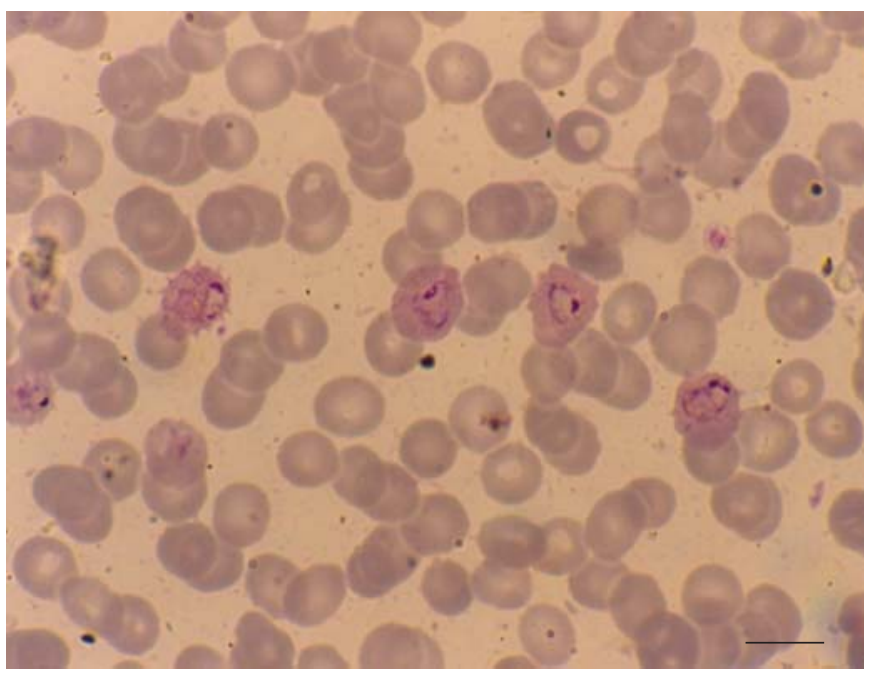

FIGURE 10. Plasmodium vivax: infected red blood cell containing a stained trophozoite showing the typically amoeboid appearance in a Giemsa thin blood film. Scale $\operatorname{bar}=7 \mu \mathrm{m}$.

respiratory distress syndrome, in which both $P$. falciparum [170-172] and P. vivax [173-179] are implicated.

The clinical impact of malaria on the lung may range from mild, with fever, cough, dyspnoea, expectoration and thoracic pain $[180,181]$, to serious respiratory insufficiency requiring admittance to an intensive care unit [182].

Radiological examination reveals the presence of small diffuse and bilateral infiltrates, with a marked increase of the vascular net and areas of lobar consolidation [183]. Associated pleural discharge may also be observed.

In the anatomopathological examination, macroscopically, the lungs appear congested and oedematose, with numerous haemorrhagic focal areas. The coexistence of pleural and/or pericardial discharge may be observed. In histological sections, pleural oedema, capillary congestion, hyaline membranes and thickening of the alveolar septa are evident. The presence of a brown pigment (haemozoin, or malarial pigment) may be observed in the interior of the alveolar macrophages. A case of obliterating bronchiolitis with organisational pneumonia associated to $P$. vivax is described in the literature, with therapeutic response to corticoids [184].

Visualisation of the protozoon through microscopic examination of the blood is the diagnostic method of choice, although there may be recourse to other diagnostic techniques, including PCR, for a correct identification of the species [185].

As well as depending on the appropriate support treatment to control haemodynamic and respiratory function, antimalarial drug therapy depends on a series of factors, such as the type of species, clinical state of the patient and the susceptibility of the parasite to the drugs, especially in relation to the area where the infection was acquired. One noteworthy aspect is the pulmonary toxicity that may be produced by the use of mefloquine, with the development of diffuse alveolar damage [186-188]. 


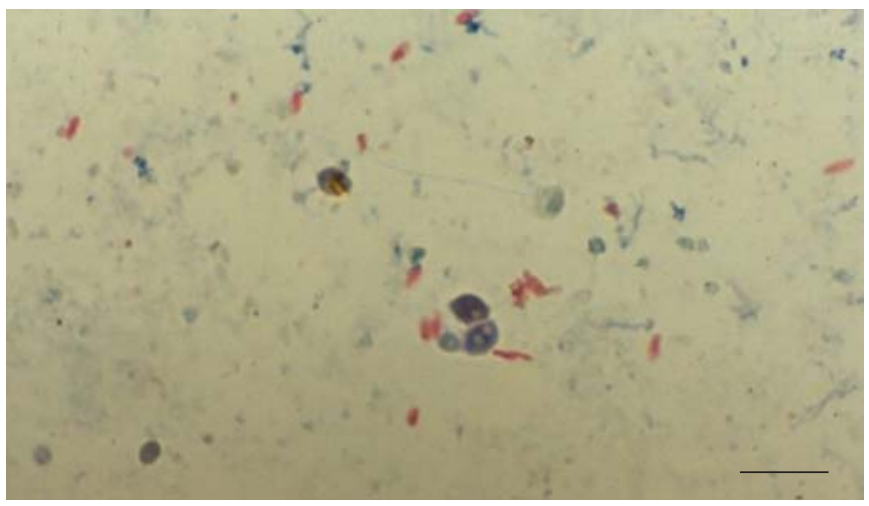

FIGURE 11. Encephalitozoon hellem: spores stained with a modified trichrome stain in bronchoalveolar lavage. Scale bar $=6 \mu \mathrm{m}$.

\section{Genus Babesia}

The Babesias are intraerythrocytic protozoa of which there exist various species, fundamentally $B$. divergens and B. microti. Their principal reservoirs are cattle and wild rodents. Humans acquire the infection (babesiosis), characterised fundamentally by the presence of fever and haemolysis, through tick bites. Among the factors of risk for systemic infection are immunosuppression, advanced age and antecedents of splenectomy. Babesiosis is quite a rare disease, in which the effect on the lung is, as is the case with malaria, a consequence of a systemic inflammatory response [189], which, in some cases, may be secondary to the antiprotozoa therapy employed [190, 191]. Among the clinical manifestations are fever, cough and laboured breathing, with noncardiogenic pulmonary oedema being the most frequent development [192]. Among the possible causes of this pulmonary complication are the lack of deformability of the infected red blood cells as they pass through the pulmonary capillaries and an increase in their adhesiveness to the vessel walls.

In the literature there are three cases in which acute respiratory distress syndrome developed as a complication of the disease $[193,194]$, with mechanical ventilation being required due to respiratory failure and hypoxaemia. In the radiological examinations, bilateral infiltrates with an alveolar pattern and thickening of the septa are described [195]. In one of the cases, the post mortem findings showed marked congestion and pulmonary consolidation; in the histological sections, hyperplasia of type II-pneumocytes, interstitial oedema and foci of formation of hyaline membranes are observed.

The diagnosis of babesiosis is established with the observation of intraerythrocytary parasites with characteristic morphology (gemmated or "Maltese cross" shapes) in peripheral blood. Techniques such as PCR allow a more specific diagnosis. The treatment of choice is the joint administration of clindamycin and quinine sulphate.

\section{Phylum Microspora}

The protozoa belonging to this phylum are intracellular obligate parasites (they lack organs such as mitochondria and Golgi apparatus). Their life cycle consists of an infective extracellular phase and a multiplication phase in the host cell, with spores, made up of small encapsulated elements $(1-4 \mu \mathrm{m}$

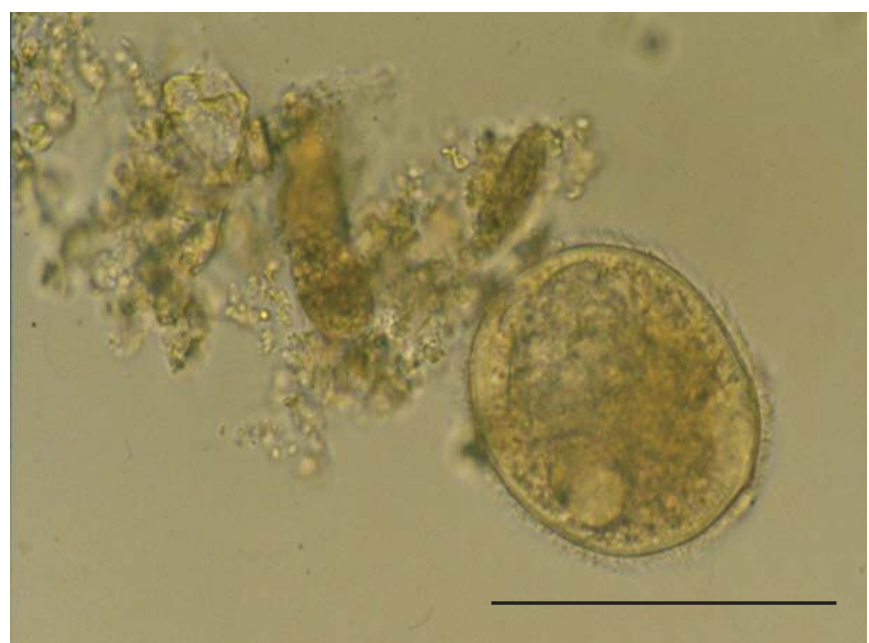

FIGURE 12. Balantidium coli: trophozoite in wet mount stained with iodine. Scale bar $=200 \mu \mathrm{m}$.

in diameter, oval morphology), as the infecting forms [196]. Of the eight kinds implicated in human pathology, the most frequent species are Enterocytozoon bieneusi, Encephalitozoon cuniculi, Encephalitozoon hellem and Encephalitozoon intestinalis.

In an immunocompetent person, microsporidiosis may be an asymptomatic infection or cause mild diarrhoeic episodes, while in immunodepressed patients the infection acquires particular importance, the most frequent form being gastrointestinal, although multiorganic repercussions also exist [197, 198]. Oral, ocular, sexual and respiratory transmission routes are described, the latter being confirmed by the observation of micro-organisms in the sputum and in the tracheobronchial tree $[199,200]$.

All the documented cases of pulmonary microsporidiosis correspond to immunodepressed patients, the predisposing factors being AIDS [201-204] and bone marrow transplant recipients [205-207]. Prominent among the possible mechanisms by which the micro-organisms colonise the respiratory apparatus are inhalation, regurgitation, orofaecal contamination and haematogenous dissemination from an intestinal focus [208].

Among the clinical manifestations of infection of the respiratory apparatus by microsporidia are rhinosinusitis [209], fever, persistent cough, dyspnoea and acute respiratory distress that, in some cases, developed before the patients' death due to cardiorespiratory failure.

Noteworthy in radiographic examinations is the presence of infiltrates and bilateral pulmonary opacities, along with the existence of areas of extensive consolidation.

The samples in which the micro-organism have been identified are nasal secretions, sputa, tracheobronchial aspirate and bronchoalveolar lavage (fig. 11), in which it was possible to carry out staining (Weber's modified trichromic and calcofluor), immunofluorescence, electron microscopy and specific cell cultures [210, 211].

In those cases in which an anatomopathological examination was performed, the biopsies show bronchiolitis with epithelial 
inflammatory infiltrate due to lymphocytes. In the necropsies, the lungs presented multiple areas of abscess, especially in the subpleural area.

Although therapy depends on the species involved and the immunological state of the patient, albendazole and fumagaline are two of the compounds habitually used.

\section{Phylum Ciliophora (ciliates)}

The fundamental feature of these protozoa is the presence of cilia, along the whole of the cellular membrane or at specific locations, which are used both for movement and for food capture. Until now, the only species known to produce pathology in humans is Balantidium coli; the only species in this genus. This is one of the largest protozoa $(50-300 \mu \mathrm{m}$ in length), with an ovoid body covered with cilia (fig. 12). Its principal natural habitat and reservoir is the large intestine of the pig, although it also inhabits that of humans. Although there is controversy as to the way this protozoon is acquired by humans, an important factor would seem to be some relation with pigs. Even so, person-to-person transmission should also be considered. Infection in humans fundamentally affects the colon, provoking clinical situations of variable intensity, ranging from asymptomatic forms to severe diarrhoea with ulceration of the mucosa.

Pulmonary infection by B. coli is quite rare, with few cases described in the literature. Among the predisposing factors are, fundamentally, immunosuppression [212, 213] and contact with pigs [214, 215], although a case has also been described of a patient with antecedents of asthma who was not immunodepressed [216]. Although the mechanism by which the lungs are affected is not completely clear, haematogenous and lymphatic dissemination by ulceration of the intestine and also, in the case of perforation, through the diaphragm, seems probable. In the majority of cases, the following are among the clinical manifestations: fever, nonproductive and persistent cough, dyspnoea of variable intensity (one of the patients required assisted respiration) and thoracic pain. Noteworthy in the radiological examinations was the presence of diffuse and bilateral interstitial infiltrates. In the examination of fresh samples, whether obtained by aspiration or by bronchoalveolar lavage, the presence of numerous trophozoites is described.

Metronidazole or tetracycline therapy seems to be effective.

\section{ACKNOWLEDGEMENTS}

The authors would like to thank J. Mosquera-Osés, radiologist of the Hospital Juan Canalejo (La Coruña, Spain), for his help with radiographic images.

\section{REFERENCES}

1 Cavalier-Smith T. Kingdom protozoa and its 18 phyla. Microbiol Rev 1993; 57: 953-994.

2 Levine ND, Corliss JO, Cox FE, et al. A newly revised classification of the protozoa. J Protozool 1980; 27: 37-58.

3 Lednicky JA, Rayner JO. Uncommon respiratory pathogens. Curr Opin Pulm Med 2006; 12: 235-239.

4 Vijayan VK. How to diagnose and manage common parasitic pneumonias. Curr Opin Pulm Med 2007; 13: 218-224.
5 Drugs for Parasitic Infections. Treatment Guidelines from The Medical Letter. Vol. 5. New Rochelle, The Medical Letter, 2007. pp. 1-15.

6 Ibarra-Pérez C. Thoracic complications of amoebic abscess of the liver: report of 501 cases. Chest 1981; 79: 672-677.

7 Roberts PP. Parasitic infections of the pleural space. Semin Respir Infect 1988; 3: 362-382.

8 Lyche KD, Jensen WA. Pleuropulmonary amebiasis. Semin Respir Infect 1997; 12: 106-112.

9 García Uribe JA, Padua Gabriel A, Quintana O, García Vázquez A, de la Escosura G. 3 cases of hematogenous lung abscess of amebic origin. Rev Invest Clin 1991; 43; 264-268.

10 Lichtenstein A, Kondo AT, Visvesvara GS, et al. Pulmonary amoebiasis presenting as superior vena cava syndrome. Thorax 2005; 60: 350-352.

11 Thorsen S, Ronne-Rasmussen J, Petersen E, Isager H, Seefeldt T, Mathiesen L. Extra-intestinal amebiasis: clinical presentation in a non-endemic setting. Scand $J$ Infect Dis 1993; 25: 747-750.

12 Shamsuzzaman SM, Hashiguchi Y. Thoracic amebiasis. Clin Chest Med 2002; 23: 479-492.

13 Mandal SK, Chakraborty PP, Bhattacharjee R, Chowdhury SR, Majumdar S. An unusual cause of dyspnoea complicating right upper abdominal swelling. World J Gastroenterol 2006; 12: 4109-4111.

14 Mbaye PS, Koffi N, Camara P, Burgel PR, Hovette P, Klotz F. Pleuropulmonary manifestations of amebiasis. Rev Pneumol Clin 1998; 54: 346-352.

15 Landay MJ, Setiawan H, Hirsch G, Christensen EE, Conrad MR. Hepatic and thoracic amebiasis. Am J Roentgenol 1980; 135: 449-454.

16 Huch Boni RA, Peter J, Marincek B. Amebic abscess of the liver manifested by "hemoptysis": US, CT and MRI findings. Abdom Imaging 1995; 20: 214-216.

17 Blayac PM, Maubon A, Ferru JM, Berges P, Reynaud D, Rouanet JP. Hepatic abscess with hepato-bronchial fistula. J Radiol 1997; 78: 469-471.

18 Walsh TJ, Berkman W, Brown NL, Padleckas R, Jao W, Mond E. Cytopathologic diagnosis of extracolonic amebiasis. Acta Cytol 1983; 27: 671-675.

19 Bhambhani S, Kashyap V. Amoebiasis: diagnosis by aspiration and exfoliative cytology. Cytopathology 2001; 12: 329-333.

20 Kennedy D, Sharma OP. Hemoptysis in a 49-year-old man. An unusual presentation of a sporadic disease. Chest 1990; 98: 1275-1278.

21 Hara A, Hirose Y, Mori H, Iwao H, Kato T, Kusuhara Y. Cytopathologic and genetic diagnosis of pulmonary amebiasis: a case report. Acta Cytol 2004; 48: 547-550.

22 Dao AH, Robinson DP, Wong SW. Frequency of Entamoeba gingivalis in human gingival scrapings. Am J Clin Pathol 1983; 80: 380-383.

23 Rosenberg M, Rachman R. Entamoeba gingivalis in sputum. Its distinction from Entamoeba histolytica. Acta Cytol 1970; 14: 361-362.

24 Dao AH. Entamoeba gingivalis in sputum smears. Acta Cytol 1985; 29: 632-633.

25 Schuster FL, Visvesvara GS. Free-living amoebae as opportunistic and non-opportunistic pathogens of humans and animals. Int J Parasitol 2004; 34: 1001-1027. 
26 Winiecka-Krusnell J, Linder E. Bacterial infections of freeliving amoebae. Res Microbiol 2001; 152: 613-619.

27 Greub G, Raoult D. Microorganisms resistant to freeliving amoebae. Clin Microbiol Rev 2004; 17: 413-433.

28 Horn M, Wagner M. Bacterial endosymbionts of freeliving amoebae. J Eukaryot Microbiol 2004; 51: 509-514.

29 Hilbi H, Weber SS, Ragaz C, Nyfeler Y, Urwyler S. Environmental predators as models for bacterial pathogenesis. Environ Microbiol 2007; 9: 563-575.

30 Shadrach WS, Rydzewski K, Laube U, et al. Balamuthia mandrillaris, free-living amoeba and opportunistic agent of encephalitis, is a potential host for Legionella pneumophila bacteria. Appl Environ Microbiol 2005; 71: 2244-2249.

31 Albert-Weissenberger C, Cazalet C, Buchrieser C. Legionella pneumophila - a human pathogen that coevolved with fresh water protozoa. Cell Mol Life Sci 2006; 64: 432-448.

32 Whan L, Grant IR, Rowe MT. Interaction between Mycobacterium avium subsp. paratuberculosis and environmental protozoa. BMC Microbiol 2006; 6: 63.

33 Thomas V, McDonnell G. Relationship between mycobacteria and amoebae: ecological and epidemiological concerns. Lett Appl Microbiol 2007; 45: 349-357.

34 Essig A, Heinemann M, Simnacher U, Marre R. Infection of Acanthamoeba castellanii by Chlamydia pneumoniae. Appl Environ Microbiol 1997; 63: 1396-1399.

35 Abd H, Johansson T, Golovliov I, Sandström G, Forsman M. Survival and growth of Fracisella tularensis in Acanthamoeba castellanii. Appl Environ Microbiol 2003; 69: 600-606.

36 Berger P, Papazian L, Drancourt M, La Scola B, Auffray JP, Raoult D. Ameba-associated microorganisms and diagnosis of nosocomial pneumonia. Emerg Infect Dis 2006; 12: 248-255.

37 Martinez AJ, Markowitz SM, Duma RJ. Experimental pneumonitis and encephalitis caused by acanthamoeba in mice: pathogenesis and ultrastructural features. J Infect Dis 1975; 131: 692-699.

38 Willaert E, Stevens AR. Experimental pneumonitis induced by Naegleria fowleri in mice. Trans $R$ Soc Trop Med Hyg 1980; 74: 779-783.

39 Westmoreland SV, Rosen J, MacKey J, et al. Necrotizing meningoencephalitis and pneumonitis in a simian immunodeficiency virus-infected rhesus macaque due to Acanthamoeba. Vet Pathol 2004; 41: 398-404.

40 Khan M, La Scola B, Lepidi H, Raoult D. Pneumonia in mice inoculated experimentally with Acanthamoeba polyphaga mimivirus. Microb Pathog 2007; 42: 56-61.

41 Yagi S, Booton GC, Visvesvara GS, Schuster FL. Detection of Balamuthia mitochondrial 16S rRNA gene DNA in clinical specimens by PCR. J Clin Microbiol 2005; 43: 3192-3197.

42 Mutreja D, Jalpota Y, Madan R, Tewari V. Disseminated acanthamoeba infection in a renal transplant recipient: a case report. Indian J Pathol Microbiol 2007; 50: 346-348.

43 Visvesvara GS, Moura H, Schuster FL. Pathogenic and opportunistic free-living amoebae: Acanthamoeba spp., Balamuthia mandrillaris, Naegleria fowleri, and Sappinia diploidea. FEMS Immunol Med Microbiol 2007; 50: 1-26.

44 Newsome AL, Curtis FT, Culbertson CG, Allen SD. Identification of acanthamoeba in bronchoalveolar lavage specimens. Diagn Cytopathol 1992; 8: 231-234.
45 Shin HJ, Im K. Pathogenic free-living amoebae in Korea. Korean J Parasitol 2004; 42: 93-119.

46 Siripanth C, Punpoowong B, Riganti M. Early detection and identification of amphizoic amoebae from nasal exudates of a symptomatic case. J Med Assoc Thai 2005; 88: 545-549.

47 McLaren LC, Davis LE, Healy GR, James CG. Isolation of Trichomonas vaginalis from the respiratory tract of infants with respiratory disease. Pediatrics 1983; 71: 888-890.

48 Hiemstra I, Van Bel F, Berger HM. Can Trichomonas vaginalis cause pneumonia in newborn babies? $\mathrm{Br}$ Med J 1984; 289: 355-356.

49 Duboucher C, Noël C, Durand-Joly I, et al. Pulmonary coinfection by Trichomonas vaginalis and Pneumocystis sp. as a novel manifestation of AIDS. Hum Pathol 2003; 34: 508-511.

50 Duboucher C, Gerbod D, Noel C, et al. Frequency of trichomonads as coinfecting agents in Pneumocystis pneumonia. Acta Cytol 2005; 49: 273-277.

51 Duboucher C, Caby S, Pierce RJ, Capron M, Dei-Cas E, Viscogliosi E. Trichomonads as superinfecting agents in Pneumocystis pneumonia and acute respiratory distress syndrome. J Eukaryot Microbiol 2006; 53: Suppl. 1, S95-S97.

52 Duboucher C, Barbier C, Beltramini A, et al. Pulmonary superinfection by Trichomonads in the course of acute respiratory distress syndrome. Lung 2007; 185: 295-301.

53 Temesvári P, Kerekes A, Tege A, Szarka K. Demonstration of Trichomonas vaginalis in tracheal aspirates in infants with early respiratory failure. J Matern Fetal Neonatal Med 2002; 11: 347-349.

54 Smith LM, Wang M, Zangwill K, Yeh S. Trichomonas vaginalis infection in a premature newborn. I Perinatol 2002; 22: 502-503.

55 Carter JE, Whithaus KC. Neonatal respiratory tract involvement by Trichomonas vaginalis: a case report and review of the literature. Am J Trop Med Hyg 2008; 78: 17-19.

56 Hoffman DJ, Brown GD, Wirth FH, Gebert BS, Bailey CL, Anday EK. Urinary tract infection with Trichomonas vaginalis in a premature infant and the development of chronic lung disease. J Perinatol 2003; 23: 59-61.

57 Hersh SM. Pulmonary trichomoniasis and Trichomonas tenax. J Med Microbiol 1985; 20: 1-10.

58 Shiota T, Arizono N, Morimoto T, Shimatsu A, Nakao K. Trichomonas tenax empyema in an immunocompromised patient with advanced cancer. Parasite 1998; 5: 375-377.

59 Ha GY, Kim MY, Kim SS, Kim SJ, Lee YH. A case of pulmonary trichomoniasis. Korean J Clin Pathol 2001; 21: 485-489.

60 Osborne PT, Giltman LI, Uthman EO. Trichomonads in the respiratory tract. A case report and literature review. Acta Cytol 1984; 28: 136-138.

61 Radosavljevic-Asic G, Jovanovic D, Radovanovic D, Tucakovic M. Trichomonas in pleural effusion. Eur Respir J 1994; 7: 1906-1908.

62 Lewis KL, Doherty DE, Ribes J, Seabolt JP, Bensadoun ES. Empyema caused by trichomonas. Chest 2003; 123: 291-292.

63 Wang HK, Jerng JS, Su KE, Chang SC, Yang PC. Trichomonas empyema with respiratory failure. Am J Trop Med Hyg 2006; 75: 1234-1236. 
64 El Kamel A, Rouetbi N, Chakroun M, Battikh M. Pulmonary eosinophilia due to Trichomonas tenax. Thorax 1996; 51: 554-555.

65 Mahmoud MS, Rahman GA. Pulmonary trichomoniasis: improved diagnosis by using polymerase chain reaction targeting Trichomonas tenax $18 \mathrm{~S}$ rRNA gene in sputum specimens. J Egypt Soc Parasitol 2004; 34: 197-211.

66 Mallat H, Podglajen I, Lavarde V, Mainardi JL, Frappier J, Cornet M. Molecular characterization of Trichomonas tenax causing pulmonary infection. J Clin Microbiol 2004; 42: 3886-3887.

67 Memik F. Trichomonads in pleural effusion. JAMA 1968; 204: 1145-1146.

68 Jongwutiwes S, Silachamroon U, Putaporntip C. Pentatrichomonas hominis in empyema thoracics. Trans $R$ Soc Trop Med Hyg 2000; 94: 185-186.

69 Kutisova K, Kulda J, Cepicka I, et al. Tetratrichomonads from the oral cavity and respiratory tract of humans. Parasitology 2005; 131: 309-319.

70 Duboucher C, Caby S, Dufernez F, et al. Molecular identification of Tritrichomonas foetus-like organisms as coinfecting agents of human Pneumocystis pneumonia. J Clin Microbiol 2006; 44: 1165-1168.

71 Zhou YP, Zhu XJ, Li M, Liu H, Chen YS. [Clinical analysis of bronchopulmonary infection with hypermastigotes: a report of two cases and review of the Chinese literature]. Zhonghua Jie He He Hu Xi Za Zhi 2006; 29: 23-25.

72 Nie XM, Yao XP, Huang Y, Zhou DY, Chang ZS, Li Q. [Amiodarone pneumonitis with Hypermastigote lung infection: a case report and review of the literatures]. Zhonghua Jie He He Hu Xi Za Zhi 2006; 29: 310-312.

73 Wang Y, Tang Z, Ji S, et al. Pulmonary Lophomonas blattarum infection in patients with kidney allograft transplantation. Transpl Int 2006; 19: 1006-1013.

74 Ribas A, Mosquera JA. Ameboflagellates in bronchial asthma. Acta Cytol 1998; 42: 685-690.

75 Ribas A, Jou C, Escobar J. Ciliocythophthoria and ameboflagellates. Acta Cytol 2003; 47: 705-708.

76 Ribas A, Martínez-Girón R, Sánchez-del-Río J, González Alonso D. Protozoal forms in the sputum of immunocompromized patients. Scand J Infect Dis 2005; 37: 205-210.

77 Ribas A, Martínez-Girón R, Ponte-Mittelbrum C, AlonsoCuervo R, Iglesias-Llaca F. Immunosupression, flagellated protozoa in the human airways and metronidazole: observations on the state of the art. Transpl Int 2007; 20: 811-812.

78 Ribas A, Martínez-Girón R. Protozoal forms in housedust mites and respiratory allergy. Allergy Asthma Proc 2006; 27: 347-349.

79 Martínez-Girón R, Ribas A. Asthma, cockroaches, and protozoal forms: chance or not chance? Ann Allergy Asthma Immunol 2006; 97: 818-819.

80 Martínez-Girón R, Ribas A, Astudillo-González A. Flagellated protozoa in cockroaches and sputum: the unhygienic connection? Allergy Asthma Proc 2007; 28: 608-609.

81 Herwaldt BL. Leishmaniasis. Lancet 1999; 354: 1191-1199.

82 Matheron S, Cabié A, Parquin F, et al. Visceral leishmaniasis and HIV infection: unusual presentation with pleuropulmonary involvement, and effect of secondary prophylaxis. AIDS 1992; 6: 238-240.

83 Alvar J, Cañavate C, Gutiérrez-Solar B, et al. Leishmania and human immunodeficiency virus coinfection: the first 10 years. Clin Microbiol Rev 1997; 10: 298-319.

84 Goncalves R, Tafuri WL, de Melo MN, Raso P, Tafuri WL. Chronic interstitial pneumonitis in dogs naturally infected with Leishmania (Leishmania) chagasi: a histopathological and morphometric study. Rev Inst Med Trop Sao Paulo 2003; 45: 153-158.

85 Duarte MI, da Matta VL, Corbett CE, Laurenti MD, Chebabo R, Goto H. Interstitial pneumonitis in human visceral leishmaniasis. Trans R Soc Trop Med Hyg 1989; 83: 73-76.

86 Marshall BG, Kropf P, Murray K, et al. Bronchopulmonary and mediastinal leishmaniasis: an unusual clinical presentation of Leishmania donovani infection. Clin Infect Dis 2000; 30: 764-769.

87 Chenoweth CE, Singal S, Pearson RD, Betts RF, Markovitz DM. Acquired immunodeficiency syndromerelated visceral leishmaniasis presenting in a pleural effusion. Chest 1993; 103: 648-649.

88 Muñoz-Rodríguez FJ, Padró S, Pastor P, et al. Pleural and peritoneal leishmaniasis in an AIDS patient. Eur J Clin Microbiol Infect Dis 1997; 16: 246-248.

89 Herrejón A, Cervera A, Maciá M, Ferrer R, Blanquer R. Adenoma bronquioloalveolar asociado a bronquiolitis obliterante y leishmaniasis pulmonar en el sida [Bronchoalveolar adenoma associated with bronchiolitis obliterans and leishmaniasis with lung involvement in acquired immunodeficiency syndrome]. Arch Bronconeumol 2005; 41: 233-235.

90 Rosenthal E, Marty P, Pesce A. Leishmania in bronchoalveolar lavage. Ann Intern Med 1991; 114: 1064-1065.

91 Jopikii L, Salmela K, Saha H, et al. Leishmaniasis diagnosed from bronchoalveolar lavage. Scand J Infect Dis 1992; 24: 677-681.

92 González-Anglada MI, Peña JM, Barbado FJ, et al. Two cases of laryngeal leishmaniasis in patients infected with HIV. Eur J Clin Microbiol Infect Dis 1994; 13: 509-511.

93 Cánovas DL, Carbonell J, Torres J, Altés J, Buades J. Laryngeal leishmaniasis as initial opportunistic disease in HIV infection. J Laryngol Otol 1994; 108: 1089-1092.

94 Navarro Cunchillos M, Villanueva Marcos JL, TorreCisneros J, Ostos Aumente P, López-Rubio F, López Villarejo P. Isolated laryngeal leishmaniasis in an immunocompetent patient: successful treatment with surgery. J Laryngol Otol 1994; 108: 249-251.

95 Grant A, Sparaggs PD, Grant HR, Bryceson AD. Laryngeal leishmaniasis. J Laryngol Otol 1994; 1086-1088.

96 Guddo F, Gallo E, Cillari E, et al. Detection of leishmania infantum kinetoplast DNA in laryngeal tissue from an immunocompetent patient. Hum Pathol 2005; 36: 1140-1142.

97 Sundar S, Rai M. Treatment of visceral leishmaniasis. Expert Opin Pharmacother 2005; 6: 2821-2829.

98 Lemle A. Chagas' disease. Chest 1999; 115: 906.

99 Camara EJN, Lima JAC, Oliveira GB, Machado AS. Pulmonary findings in patients with chagasic megaesophagus. Chest 1983; 83: 87-91.

100 Melnikov VG, Fierro Velasco F, Espinoza Gómez F, Guzmán Rodríguez F, Dobrovinskaya OR. Pathologic 
changes in lungs caused by Mexican isolates of Trypanosoma cruzi in the acute phase of infection in mice. Am J Trop Med Hyg 2005; 73: 301-306.

101 Bittencourt AL, Rodrigues de Freitas LA, Galvao de Araujo MO, Jácomo K. Pneumonitis in congenital Chagas' disease. A study of ten cases. Am J Trop Med Hyg 1981; 30: 38-42.

102 Mansfield LS, Gajadhar AA. Cyclospora cayetanensis, a food- and waterborne coccidian parasite. Vet Parasitol 2004; 126: 73-90.

103 Di Gliullo AB, Cribari MS, Bava AJ, Cicconetti JS, Collazos R. Cyclospora cayetanensis in sputum and stool samples. Rev Inst Med Trop Sao Paulo 2000; 42: 115-117.

104 Hussein EM, Abdul-Manaem AH, el-Attary SL. Cyclospora cayetanensis oocysts in sputum of a patient with active pulmonary tuberculosis, case report in Ismailia, Egypt. J Egypt Soc Parasitol 2005; 35: 787-793.

105 Xiao L, Fayer R, Ryan U, Upton SJ. Cryptosporidium taxonomy: recent advances and implications for public health. Clin Microbiol Rev 2004; 17: 72-97.

106 Hunter PR, Nichols G. Epidemiology and clinical features of Cryptosporidium infection in immunocompromised patients. Clin Microbiol Rev 2002; 15: 145-154.

107 Forgacs P, Tarshis A, Ma P, et al. Intestinal and bronchial cryptosporidiosis in an immunodeficient homosexual man. Ann Intern Med 1983; 99: 793-794.

108 Brady EM, Margolis ML, Korzeniowski OM. Pulmonary cryptosporidiosis in acquired immune deficiency syndrome. JAMA 1984; 252: 89-90.

109 Ma P, Villanueva TG, Kaufmann D, Gillooley JF. Respiratory cryptosporidiosis in acquired immune deficiency syndrome. JAMA 1984; 252: 1298-1301.

110 Hojlyng N, Jensen BN. Respiratory cryptosporidiosis in HIV-positive patients. Lancet 1988; 1: 590-591.

111 Moore JA, Frenkel JK. Respiratory and enteric cryptosporidiosis in humans. Arch Pathol Lab Med 1991; 115: 1160-1162.

112 Brea Hernando AJ, Bandres Franco E, Mosquera Lozano JD, Lantero Benedito M, Ezquerra Lezcano M. [Pulmonary cryptosporidiosis and AIDS. Presentation of a case and review of the literature]. An Med Interna 1993; 10: 232-236.

113 López-Vélez R, Tarazona R, Garcia Camacho A, et al. Intestinal and extraintestinal cryptosporidiosis in AIDS patients. Eur J Clin Microbiol Infect Dis 1995; 14: 677-681.

114 Meynard JL, Meyohas MC, Binet D, Chouaid C, Frottier J. Pulmonary cryptosporidiosis in the acquired immunodeficiency syndrome. Infection 1996; 24: 328-331.

115 Clavel A, Arnal AC, Sanchez EC, et al. Respiratory cryptosporidiosis: case series and review of the literature. Infection 1996; 24: 341-346.

116 Pellicelli AM, Palmieri F, Spinazzola F, et al. Pulmonary cryptosporidiosis in patients with acquired immunodeficiency syndrome. Minerva Med 1998; 89: 173-175.

117 Travis WD, Schmidt K, MacLowry JD, Masur $\mathrm{H}$, Condron KS, Fojo AT. Respiratory cryptosporidiosis in a patient with malignant lymphoma. Report of a case and review of the literature. Arch Pathol Lab Med 1990; 114: 519-522.

118 Kibbler CC, Smith A, Hamilton-Dutoit SJ, Milburn H, Pattinson JK, Prentice HG. Pulmonary cryptosporidiosis occurring in a bone marrow transplant patient. Scand J Infect Dis 1987; 19: 581-584.

119 Gentile G, Venditti M, Micozzi A, et al. Cryptosporidiosis in patients with hematologic malignancies. Rev Infect Dis 1991; 13: 842-846.

120 Gentile G, Baldassari L, Caprioli A, et al. Colonic vascular invasion as a possible route of extraintestinal cryptosporidiosis. Am J Med 1987; 82: 574-575.

121 Roussel F, Lemeteil D, Favennec L, Tayot J, Ballet JJ, Brasseur P. Respiratory tract cryptosporidiosis in immunosuppressed rat is associated with an epithelial metaplasia. Parasite 1995; 2: 85-87.

122 Lanzarini P, Gatti S, Bruno A, Corona S, Scaglia M. Experimental respiratory cryptosporidiosis in immunosupressed rats: a light and electron microscopy study. Parasite 1996; 6: 217-222.

123 Yanai T, Chalifoux LV, Mansfield KG, Lackner AA, Simon MA. Pulmonary cryptosporidiosis in simian immunodeficiency virus-infected rhesus macaques. Vet Pathol 2000; 37: 472-475.

124 Miller RA, Wasserheit JN, Kirihara J, Coyle MB. Detection of cryptosporidium oocysts in sputum during screening for mycobacteria. J Clin Microbiol 1984; 20: 1192-1193.

125 Dupont C, Bougnoux ME, Turner L, Rouveix E, Dorra M. Microbiological findings about pulmonary cryptosporidiosis in two AIDS patients. J Clin Microbiol 1996; 34: 227-229.

126 Mercado R, Buck GA, Manque PA, Ozaki LS. Cryptosporidium hominis infection of the human respiratory tract. Emerg Infect Dis 2007; 13: 462-464.

127 Palmieri F, Cicalini S, Froio N, et al. Pulmonary cryptosporidiosis in an AIDS patient: successful treatment with paromomycin plus azithromicyn. Int J STD AIDS 2005; 16: 515-517.

128 Mohri H, Fujita H, Asakura Y, et al. Case report: inhalation therapy of paromomycin is effective for respiratory infection and hypoxia by cryptosporidium with AIDS. Am J Med Sci 1995; 309: 60-62.

129 Leal FE, Cavazzana CL, de Andrade HF Jr, Galisteo AJ Jr, de Mendoza JS, Kallas EG. Toxoplasma gongii pneumonia in immunocompetent subjects: case report and review. Clin Infect Dis 2007; 44: 62-66.

130 Pomeroy C, Filice GA. Pulmonary toxoplasmosis: a review. Clin Infect Dis 1992; 14: 863-870.

131 Hofman P, Bernard E, Michiels JF, Thyss A, Le Fichoux Y, Loubiere R. Extracerebral toxoplasmosis in the acquired immunodeficiency syndrome (AIDS). Pathol Res Pract 1993; 189: 894-901.

132 Mendelson MH, Finkel LJ, Meyers BR, Lieberman JP, Hirschman SZ. Pulmonary toxoplasmosis in AIDS. Scand J Infect Dis 1987; 19: 703-706.

133 Oksenhendler E, Cadranel J, Sarfati C, et al. Toxoplasma gondii pneumonia in patients with the acquired immunodefiency syndrome. Am J Med 1990; 88: 18-21.

134 Schnapp LM, Geaghan SM, Campagna A, et al. Toxoplasma gondii pneumonitis in patients with the human immunodeficiency virus. Arch Intern Med 1992; 152: 1073-1077.

135 Nash G, Kerschmann RL, Herndier B, Dubey JP. The pathological manifestations of pulmonary toxoplasmosis 
in the acquired immunodeficiency syndrome. Hum Pathol 1994; 25: 652-658.

136 Rabaud C, May T, Lucet JC, Leport C, Ambroise-Thomas P, Canton P. Pulmonary toxoplasmosis in patients infected with human immunodeficiency virus: a French National Survey. Clin Infect Dis 1996; 23: 1249-1254.

137 Asensi V, Cartón JA, Maradona JA, et al. [Pulmonary toxoplasmosis. Study of 4 cases and review of the literature]. Enferm Infecc Microbiol Clin 1993; 11: 195-198.

138 Singh N, Gayowski T, Marino IR. Toxoplasma gondii pneumonitis in a liver transplant recipient: implications for diagnosis. Liver Transpl Surg 1996; 2: 299-300.

139 Saad R, Vincent JF, Cimon B, et al. Pulmonary toxoplasmosis after allogenic bone marrow transplantation: case report and review. Bone Marrow Transplant 1996; 18: 211-212.

140 Sing A, Leitritz L, Roggenkamp A, et al. Pulmonary toxoplasmosis in bone marrow transplant recipients: report of two cases and review. Clin Infect Dis 1999; 29: 429-433.

141 Munir A, Zaman M, Eltorky M. Toxoplasma gondii pneumonia in a pancreas transplant patient. South Med J 2000; 93: 614-617.

142 Mele A, Paterson PJ, Prentice HG, Leoni P, Kibbler CC. Toxoplasmosis in bone marrow transplantation: a report of two cases and systematic review of the literature. Bone Marrow Transplant 2002; 29: 691-698.

143 Fricker-Hidalgo H, Brion JP, Durand M, Chavanon O, Brenier-Pinchart MP, Pelloux H. Disseminated toxoplasmosis with pulmonary involvement after heart transplantation. Transpl Infect Dis 2005; 7: 38-40.

144 Evans TG, Schwartzman JD. Pulmonary toxoplasmosis. Semin Respir Infect 1991; 6: 51-57.

145 Mariuz P, Bosler EM, Luft BJ. Toxoplasma pneumonia. Semin Respir Infect 1997; 12: 40-43.

146 Filice GA, Clabots CR, Riciputi PE, Goñi-Laguarda O, Pomeroy $\mathrm{C}$. Changes in cytokine levels during reactivation of Toxoplasma gondii infection in lungs. Infect Immun 1999; 67: 2082-2089.

147 Gandhi S, Lyubsky S, Jimenez-Lucho V. Adult respiratory distress syndrome associated with disseminated toxoplasmosis. Clin Infect Dis 1994; 19: 169-171.

148 Ortonne N, Ribaud P, Meignin V, et al. Toxoplasmic pneumonitis leading to fatal acute respiratory distress syndrome after engraftment in three bone marrow transplant recipients. Transplantation 2001; 72: 1838-1840.

149 Charles PE, Doise JM, Quenot JP, et al. An unusual cause of acute respiratory distress in a patient with AIDS: primary infection with Toxoplasma gondii. Scand J Infect Dis 2003; 35: 901-902.

150 Goodman PC, Schnapp LM. Pulmonary toxoplasmosis in AIDS. Radiology 1992; 184: 791-793.

151 Dawis MA, Bottone EJ, Vlachos A, Burroughs MH. Unsuspected Toxoplasma gondii empyema in a bone marrow transplant recipient. Clin Infect Dis 2002; 34: 37-39.

152 Collet G, Marty P, Le Fichoux Y, et al. Pleural effusion as the first manifestation of pulmonary toxoplasmosis in a bone marrow transplant recipient. Acta Cytol 2004; 48: 114-116.

153 Jacobs F, Depierreux M, Goldman M, et al. Role of bronchoalveolar lavage in diagnosis of disseminated toxoplasmosis. Rev Infect Dis 1991; 13: 637-641.
154 Bottone EJ. Diagnosis of acute pulmonary toxoplasmosis by visualization of invasive and intracellular tachyzoites in Giemsa-stained smears of bronchoalveolar lavage fluid. J Clin Microbiol 1991; 29: 2626-2627.

155 Sternberg RI, Baughman RP, Dohn MN, First MR. Utility of bronchoalveolar lavage in assessing pneumonia in immunosuppressed renal transplant recipients. Am J Med 1993; 95: 358-364.

156 Gordon SM, Gal AA, Hertzler GL, Bryan JA, Perlino C, Kanter KR. Diagnosis of pulmonary toxoplasmosis by bronchoalveolar lavage in cardiac transplant recipients. Diagn Cytopathol 1993; 9: 650-654.

157 Laibe S, Ranque S, Curtillet C, Faraut F, Dumon H, Franck J. Timely diagnosis of disseminated toxoplasmosis by sputum examination. J Clin Microbiol 2006; 44: 646-648.

158 Bretagne S, Costa JM, Fleury-Feith J, Poron F, DubreuilLemaire ML, Vidaud M. Quantitative competitive PCR with bronchoalveolar lavage fluid for diagnosis of toxoplasmosis in AIDS patients. J Clin Microbiol 1995; 33: 1662-1664.

159 Petersen E, Edvinsson B, Lundgren B, Benfield T, Evengard B. Diagnosis of pulmonary infection with Toxoplasma gondii in immunocompromised HIV positive patients by real-time PCR. Eur J Clin Microbiol Infect Dis 2006; 25: 401-404.

160 Campagna AC. Pulmonary toxoplasmosis. Semin Respir Infect 1997; 12: 98-105.

161 Jelinek T, Schulte C, Behrens R, et al. Imported falciparum malaria in Europe: sentinel surveillance data from the European network on surveillance of imported infectious diseases. Clin Infect Dis 2002; 34: 572-576.

162 Pérez-Arellano JL, Carranza C. Infecciones respiratorias importadas: nuevos retos y amenazas [Imported respiratory infections: new challenges and threats]. Arch Bronconeumol 2003; 39: 289-291.

163 Anstey NM, Jacups SP, Cain T, et al. Pulmonary manifestations of uncomplicated falciparum and vivax malaria: cough, small airways obstruction, impaired gas transfer, and increased pulmonary phagocytic activity. $J$ Infect Dis 2002; 185: 1326-1334.

164 Hovette P, Camara P, Burgel PR, Mbaye PS, Sane M, Klotz F. Pulmonary manifestations associated with malaria. Rev Pneumol Clin 1998; 54: 340-345.

165 Taylor WR, White NJ. Malaria and the lung. Clin Chest Med 2002; 23: 457-468.

166 Illamperuma C, Allen BL. Pulmonary edema due to Plasmodium vivax malaria in an American missionary. Infection 2007; 35: 374-376.

167 Taylor WR, Cañon V, White NJ. Pulmonary manifestations of malaria: recognition and management. Treat Respir Med 2006; 5: 419-428.

168 Muanza K, Gay F, Behr C, Schert A. Primary culture of human lung microvessel endothelial cells: a useful in vitro model for studying Plasmodium falciparum-infected erythrocyte cytoadherence. Res Immunol 1996; 147: 149-163.

169 Traoré B, Muanza K, Looareesuwan S, et al. Cytoadherence characteristics of Plasmodium falciparum isolates in Thailand using an in vitro human lung endothelial cells model. Am J Trop Med Hyg 2000; 62: $38-44$. 
170 Gachot B, Wolff M, Nissack G, Veber B, Vachon F. Acute lung injury complicating imported Plasmodium falciparum malaria. Chest 1995; 108: 746-749.

171 Asiedu DK, Sherman CB. Adult respiratory distress syndrome complicating Plasmodium falciparum malaria. Heart Lung 2000; 29: 294-297.

172 Maguire GP, Handojo T, Pain MC, et al. Lung injury in uncomplicated and severe falciparum malaria: a longitudinal study in Papua, Indonesia. J Infect Dis 2005; 192: 1966-1974.

173 Carlini ME, White AC Jr, Atmar RL. Vivax malaria complicated by adult respiratory distress syndrome. Clin Infect Dis 1999; 28: 1182-1183.

174 Tanios MA, Kogelman L, McGovern B, Hassoun PM. Acute respiratory distress syndrome complicating Plasmodium vivax malaria. Crit Care Med 2001; 29: 665-667.

175 Habib AG, Singh KS. Respiratory distress in nonimmune adults with imported malaria. Infection 2004; 32: 356-359.

176 Lomar AV, Vidal JE, Lomar FP, Barbas CV, de Matos GJ, Boulos M. Acute respiratory distress syndrome due to vivax malaria: case report and literature review. Braz J Infect Dis 2005; 9: 425-430.

177 Kumar S, Melzer M, Dodds P, Watson J, Ord R. P. vivax malaria complicated by shock and ARDS. Scand J Infect Dis 2007; 39: 255-256.

178 Price L, Planche T, Rayner C, Krishna S. Acute respiratory distress syndrome in Plasmodium vivax malaria: case report and review of the literature. Trans R Soc Trop Med Hyg 2007; 101: 655-659.

179 Maguire JD, Fenton ME, Susanti AI, Walker JB. Plasmodium vivax-associated acute respiratory distress syndrome after extended travel in Afghanistan. Travel Med Infect Dis 2007; 5: 301-305.

180 Gozal D. The incidence of pulmonary manifestations during Plasmodium falciparum malaria in non immune subjects. Trop Med Parasitol 1992; 43: 6-8.

181 Rajput R, Singh H, Singh S, Tiwari UC. Pulmonary manifestations in malaria. J Indian Med Assoc 2000; 98: 612-614.

182 Bruneel F, Hocqueloux L, Alberti C, et al. The clinical spectrum of severe imported falciparum malaria in the intensive care unit: report of 188 cases in adults. Am J Respir Crit Care Med 2003; 167: 684-689.

183 Cayea PD, Rubin E, Teixidor HS. Atypical pulmonary malaria. Am J Roentgenol 1981; 137: 51-55.

184 Yale SH, Adlakha A, Sebo TJ, Ryu JH. Bronchiolitis obliterans organizing pneumonia caused by Plasmodium vivax malaria. Chest 1993; 104: 1294-1296.

185 Makler MT, Palmer CJ, Ager AL. A review of practical techniques for the diagnosis of malaria. Ann Trop Med Parasitol 1998; 92: 419-433.

186 Drent M. Drug-induced pneumonia associated with hemizygote glucose- 6 phosphate-dehydrogenase deficiency. Eur J Haematol 1998; 61: 218-220.

187 Udry E, Bailly F, Dusmet M, Schnyder P, Lemoine R, Fitting JW. Pulmonary toxicity with mefloquine. Eur Respir J 2001; 18: 890-892.

188 Soentjens P, Delanote M, van Gompel A. Mefloquineinduced pneumonitis. J Travel Med 2006; 13: 172-174.

189 Kemper CA. Pulmonary disease in selected protozoal infections. Semin Respir Infect 1997; 12: 113-121.
190 Boustani MR, Lepore TJ, Gelfand JA, Lazarus DS. Acute respiratory failure in patients treated for babesiosis. Am J Respir Crit Care Med 1994; 149: 1689-1691.

191 Byrd RP Jr, Roy TM. Acute respiratory distress syndrome following treatment for babesiosis. Expert Opin Pharmacother 2002; 3: 1541-1542.

192 Cunha BA, Nausheen S, Szalda D. Pulmonary complications of babesiosis: case report and literature review. Eur J Clin Microbiol Infect Dis 2007; 26: 505-508.

193 Gordon S, Cordon RA, Mazdzer EJ, Valigorsky JM, Blagg NA, Barnes SJ. Adult respiratory distress syndrome in babesiosis. Chest 1984; 86: 633-634.

194 Horowitz ML, Coletta F, Fein AM. Delayed onset adult respiratory distress syndrome in babesiosis. Chest 1994; 106: 1299-1301.

195 Dodd JD, Aquino SL, Sharma A. Babesiosis: CT and hematologic findings. J Thorac Imaging 2007; 22: 271-273.

196 Didier ES, Weiss LM. Microsporidiosis: current status. Curr Opin Infect Dis 2006; 19: 485-492.

197 Mertens RB, Didier ES, Fishbein MC, Bertucci DC, Rogers LB, Orenstein JM. Encephalitozoon cuniculi microsporidiosis: infection of the brain, heart, kidneys, trachea, adrenal glands, and urinary bladder in a patient with AIDS. Mod Pathol 1997; 10: 68-77.

198 Georges E, Rabaul C, Amiel C, et al. Enterocytozoon bieneusi multiorgan microsporidiosis in a HIV-infected patient. J Infect 1998; 36: 223-225.

199 Schwartz DA, Bryan RT, Hewan-Lowe KO, et al. Disseminated microsporidiosis (Encephalitozoon hellem) and acquired immunodeficiency syndrome. Autopsy evidence for respiratory acquisition. Arch Pathol Lab Med 1992; 116: 660-668.

200 Weber R, Kuster H, Visvesvara GS, Bryan RT, Schwartz DA, Lüthy R. Disseminated microsporidiosis due to Encephalitozoon hellem: pulmonary colonization, microhematuria, and mild conjunctivitis in a patient with AIDS. Clin Infect Dis 1993; 17: 415-419.

201 Weber R, Kuster H, Keller R, et al. Pulmonary and intestinal microsporidiosis in a patient with the acquired immunodeficiency syndrome. Am Rev Respir Dis 1992; 146: 1603-1605.

202 Schwartz DA, Visvesvara GS, Leitch GJ, et al. Pathology of symptomatic microsporidial (Encephalitozoon hellem) bronchiolitis in the acquired immunodeficiency syndrome: a new respiratory pathogen diagnosed from lung biopsy, bronchoalveolar lavage, sputum, and tissue culture. Hum Pathol 1993; 24: 937-943.

203 Remadi S, Dumais J, Wafa K, MacGee W. Pulmonary microsporidiosis in a patient with the acquired immunodeficiency syndrome. A case report. Acta Cytol 1995; 39: 1112-1116.

204 Scaglia M, Sacchi L, Croppo GP, et al. Pulmonary microsporidiosis due to Encephalitozoon hellem in a patient with AIDS. J Infect 1997; 34: 119-126.

205 Kelkar R, Sastry PS, Kulkarni SS, Saikia TK, Parikh PM, Advani SH. Pulmonary microsporidial infection in a patient with CML undergoing allogeneic marrow transplant. Bone Marrow Transplant 1997; 19: 179-182. 
206 Teachey DT, Russo P, Orenstein JM, Didier ES, Bowers C, Bunin N. Pulmonary infection with microsporidia after allogeneic bone marrow transplantation. Bone Marrow Transplant 2004; 33: 299-302.

207 Orenstein JM, Russo P, Didier ES, Bowers C, Bunin N, Teachey DT. Fatal pulmonary microsporidiosis due to Encephalitozoon cuniculi following allogeneic bone marrow transplantation for acute myelogenous leukemia. Ultrastruct Pathol 2005; 29: 269-276.

208 Botterel F, Minozzi C, Vittecoq D, Bourée P. Pulmonary localization of Enterocytozoon bieneusi in an AIDS patient: Case report and review. J Clin Microbiol 2002; 40: 4800-4801.

209 Franzen C, Müller A, Salzberger B, Fätkenheuer G, Diehl V, Schrappe M. Chronic rhinosinusitis in patients with AIDS: potential role of microsporidia. AIDS 1996; 10: 687-688.

210 Didier ES, Rogers LB, Orenstein JM, et al. Characterization of Encephalitozoon (Septata) intestinalis isolates cultured from nasal mucosa and bronchoalveolar lavage fluids of two AIDS patients. J Eukaryot Microbiol 1996; 43: 34-43.
211 del Aguila C, Lopez-Velez R, Fenoy S, et al. Identification of Enterocytozoon bieneusi spores in respiratory samples from an AIDS patient with a 2-year history of intestinal microsporidiosis. J Clin Microbiol 1997; 35: 1862-1866.

212 Vasilakopoulou A, Dimarongona K, Samakovli A, Papadimitris K, Avlami A. Balantidium coli pneumonia in an immunocompromised patient. Scand J Infect Dis 2003; 35: 144-146.

213 Anargyrou K, Petrikkos GL, Suller MT, et al. Pulmonary Balantidium coli infection in a leukemic patient. Am J Hematol 2003; 73: 180-183.

214 Dorfman S, Rangel O, Bravo LG. Balantidiasis: report of a fatal case with appendicular and pulmonary involvement. Trans R Soc Trop Med Hyg 1984; 78: 833-834.

215 Sharma S, Harding G. Necrotizing lung infection caused by the protozoan Balantidium coli. Can J Infect Dis Med Microbiol 2003; 14: 163-166.

216 Ladas SD, Savva S, Frydas A, Kaloviduris A, Hatzioannou J, Raptis S. Invasive balantidiasis presented as chronic colitis and lung involvement. Dig Dis Sci 1989; 34: 1621-1623. 